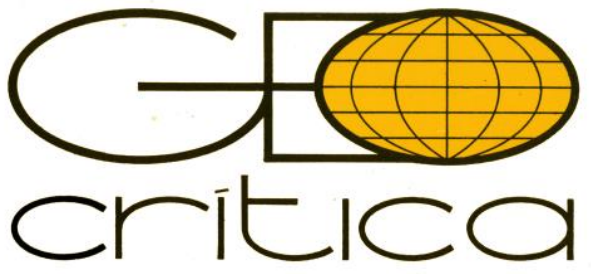

\title{
A (IN)VISIBILIDADE DA REDE TECNOPOLÍTICA BOLSONARISTA
}

\author{
Tamara Tania Cohen Egler \\ Instituto de Pesquisa e Planejamento Urbano e Regional/Universidade Federal do Rio de \\ Janeiro (IPPUR /UFRJ) \\ tamaraegler@gmail.com \\ Thiago Costa \\ Graduando de Física na UFRJ, bolsista de Iniciação Científica (IPPUR/UFRJ) \\ thiagol50297@gmail.com \\ Pedro Paulo Gonçalves \\ Mestrando do programa de Engenharia de Sistemas de Computação (COPPE/UFRJ) \\ pedropgneto@gmail.com
}

\section{A (in)visibilidade da rede tecnopolítica bolsonarista (Resumo)}

Qual foi a importância da rede tecnopolítica na eleição de Jair Bolsonaro para a presidência do Brasil? Essa pergunta, que orienta a nossa pesquisa, tem por objetivo investigar como a rede tecnopolítica orquestra uma comunicação virtual através de canais de alta fluidez e permite a formação de um coletivo coeso, que, pela mediação tecnológica, se torna um importante ator político. Para identificar os atores que participam dessa macro rede, procedemos a uma análise do espaço social virtual, aplicando a teoria dos campos de Bourdieu. Essa estratégia permitiu-nos decupar a macro rede em 8 (oito) campos, revelando como ela se forma na transversalidade das esferas política, midiática e econômica, para citar apenas as mais importantes. Metodologicamente, recorrendo à aplicação do programa Gephi, foi possível desenhar sua representação, que podemos ler em grafos, pela aplicação do programa worldclouds, foi possível identificar os principais atores nacionais e internacionais. Para tal, examinamos as relações estabelecidas entre os atores, suas práticas de comunicação e difusão, bem como os interesses que lhe deram origem. Os resultados a que chegamos deixam patente as diferentes formas de uso de redes tecnopolíticas, através das quais se desenvolvem estratégias de ação autoritárias, associadas à enunciação de uma narrativa manipulada, que cria uma realidade fictícia. Ela produz a atração rizomática de muitos seguidores, que se articulam em defesa de uma ideologia conservadora, e engendra um ator político nunca antes imaginado, que, se forma para além das formas de organização clássica em partidos políticos, vem a exercer o controle da nação e colocar em xeque a existência do Brasil como nação democrática e soberana.

Palavras-chave: rede; tecnopolítica; campos; eleições; Jair Bolsonaro. 


\section{The (in)visibility of the bolsonarismo technopolitical network (Abstract)}

What was the importance of the technopolitical network in the election of Jair Bolsonaro for the presidency of Brazil? This question, which guides our research, aims to investigate how the technopolitical network orchestrates virtual communication through highly fluid channels and allows the formation of a cohesive collective, which, through technological mediation, becomes an important political actor. In order to identify the actors that participate in this macro network, we proceeded with an analysis of the virtual social space, applying Bourdieu's theory of fields. This strategy allowed us to decouple the macro network in 8 (eight) fields, revealing how it is formed in the transversality of the political, media and economic spheres, to name only the most important ones. Methodologically, using the application of the Gephi program, it was possible to design its representation, which we can read in graphs, through the application of the worldclouds program, it was possible to identify the main national and international actors. To this end, we examine the relationships established between the actors, their communication and dissemination practices, as well as the interests that gave rise to them. The results we have obtained show the different forms of use of technopolitical networks, through which authoritarian action strategies are developed, associated with the enunciation of a manipulated narrative, which creates a fictitious reality. It produces the rhizomatic attraction of many followers, who articulate in defense of a conservative ideology, and engenders a political actor never before imagined, who, if formed in addition to the classic forms of organization in political parties, comes to exercise control of the nation and to question the existence of Brazil as a democratic and sovereign nation.

Keywords: network; technopolitics; fields; elections; Jair Bolsonaro.

\section{La (in) visibilidad de la red tecnopolítica bolsonarista (Resumen)}

¿Cuál fue la importancia de la red tecnopolítica en la elección de Jair Bolsonaro para la presidencia de Brasil? Esta pregunta, que guía nuestra investigación, tiene como objetivo indagar cómo la red tecnopolítica orquesta la comunicación virtual a través de canales altamente fluidos y permite la formación de un colectivo cohesionado, que a través de la mediación tecnológica se convierte en un actor político importante. Para identificar los actores que participan en esta macro red, se procedió a un análisis del espacio social virtual, aplicando la teoría de campos de Bourdieu. Esta estrategia permitió desacoplar la macro red en 8 (ocho) campos, revelando cómo se forma en la transversalidad de los ámbitos político, mediático y económico, por nombrar solo los más importantes. Metodológicamente, utilizando la aplicación del programa Gephi, fue posible diseñar su representación, la cual podemos leer en grafos, mediante la aplicación del programa worldclouds, fue posible identificar los principales actores nacionales e internacionales. Para ello, se examinan las relaciones que se establecen entre los actores, sus prácticas de comunicación y difusión, así como los intereses que les dieron origen. Los resultados que hemos obtenido muestran las diferentes formas de uso de las redes tecnopolíticas, a través de las cuales se desarrollan estrategias de acción autoritaria, asociadas a la enunciación de una narrativa manipulada, que crea una realidad ficticia. Produce la atracción rizomática de muchos seguidores, que se articulan en defensa de una ideología conservadora, y engendra un actor político nunca antes imaginado, que si se forma además de las formas clásicas de organización en los partidos políticos, llega a ejercer el control de la nación. y cuestionar la existencia de Brasil como nación democrática y soberana.

Palabras clave: red; tecnopolítica; campos; elecciones; Jair Bolsonaro. 


\section{Introdução}

O título do artigo já deixa clara a nossa intenção, identificar e examinar a rede tecnopolítica bolsonarista, seus atores, discursos e significados, visando, com isso, a investigar não só sua ação política, mas também seu impacto sobre a democracia do Brasil. Levamos em conta as relações entre cultura, tecnologia e política, derivadas dos fluxos de comunicação digital que sustentam a sua invisibilidade, percebida como uma cadeia de pessoas capazes de conduzir operações de desinformação ${ }^{1}$, por mediação de rede e sobre o território, no intuito de estabelecer sua dominação sobre o país.

Nos últimos anos, temos assistido a diferentes formas de uso de redes tecnopolíticas, que servem de veículo para o desenvolvimento de estratégias de ação autoritárias e que estão colocando em perigo a democracia no Brasil - e por que não dizer? - no mundo ${ }^{2}$. Para comprovar essa afirmação, examinamos as relações que se estabelecem entre os atores que participam da rede bolsonarista, suas práticas de comunicação e difusão. O discurso produzido por essa rede é fruto de uma narrativa manipulada, o que resulta na atração rizomática de muitos seguidores, que, articulados, formam uma totalidade complexa, comunicando-se por canais de alta fluidez para alcançar um determinado sentido compartilhado, conferindo significado à ação política $^{3}$.

Nossa pesquisa foi desenvolvida no contexto das eleições presidenciais de outubro de 2018, para mandato a ser iniciado em $1^{\circ}$ de janeiro de 2019 , cujos principais concorrentes foram Jair Bolsonaro, do Partido Social Liberal (PSL), e Fernando Haddad, do Partido dos Trabalhadores (PT).

Procuramos responder a algumas perguntas básicas, apresentadas a seguir:

- Como foi formado o espaço social virtual da rede bolsonarista?

- Que atores econômicos, políticos e midiáticos participaram da rede bolsonarista?

- Qual teoria podemos aplicar para proceder a uma análise sociológica do ciberespaço?

- Que traço comum identifica os atores associados à rede?

- Quais foram suas estratégias de ação política?

- Como se deu a impulsão de capital que financiou a eleição de Jair Bolsonaro?

Para justificar a importância da pesquisa, cabe relembrar que na análise das redes sociotecnicas, tem predominância a teoria da Análise das Sociais Redes - entretanto a literatura sobre o tema ${ }^{4}$ alerta para a importância da teoria associada à Análise das Redes Sociais- ARS, para revelar como as pesquisas sobre redes sociais estão, focadas nas suas complexas estruturas em que ocorrem múltiplas comunicações que articulam os membros de um mesmo sistema social. Não menos importante e perceber que elas devem ser examinadas a luz de uma observação que associa indivíduos e entidades. Essa teoria e muito importante, por que mostra como as redes são formadas por grupos que reúnem indivíduos. Sendo que as redes se formam por fluxos de comunicação digital que fazem a mediação de um conjunto de grupos. Entretanto, a categoria entidade reconhece, formas de organização de pessoa jurídica estabelecida para fins específicos,

\footnotetext{
${ }^{1}$ Empoli, 2021, p. 39.

${ }^{2}$ Castells, 2017, p. 28.

${ }^{3}$ Scherer, 2005, p. 45.

${ }^{4}$ Tomael e Marteleto, 2013, p. 2.
} 
quer dizer tem um reconhecimento no 'mundo dos sistemas'. Como as autoras indicam as metodologias existem não são suficientes para fazer a análise da complexidade dada pelas redes.

Os dados levantados na nossa pesquisa revelam que os grupos sociais que participam das redes, não estão necessariamente reconhecidos por entidades jurídicas, por essa razão optamos pelas categorias Campo de Bourdieu, que nos permite, ampliar o sentido entidade para todos os grupos sociais que participam das redes, quer seja juridicamente reconhecido, quer seja no 'mundo da vida'.

A literatura do campo é muito ampla, podemos ler um conjunto de trabalhos sobre redes na saúde, organizações da sociedade civil, sociabilidades. Nosso desígnio é compreender a sua importância da ação política. Para avançar nessa relação podemos ler em Souza \& Moraes ${ }^{5}$, a importante manifestação social que aconteceu em 2012 em Portugal, que alcançou a participação de meio milhão de pessoas. A metodologia foca no espaço político lido na plataforma do Facebook, que assume particular importância na difusão da informação e do debate político. A análise realizada revela as diferenças que existem na mobilização política tradicional e na mobilização dada pelas mediações das redes digitais. Quando demonstram a importância do espaço político criado pelas plataformas digitais. Essa metodologia é muito importante porque permite identificar e conhecer o discurso dos atores enredados na ação política.

\section{Método e metodologia}

Calcado na interdisciplinaridade, nosso método de investigação associa a teoria social, a teoria da comunicação e a teoria política. O tratamento dessas interfaces é especialmente relevante visto estarmos diante de novas formas de dominação e por elas acontecerem via mediação de sistemas de informação e comunicação, que resultam quer em processos de dominação cultural ${ }^{6}$ quer na difusão de discurso que manipula a ação política.

Essas racionalidades alternativas, que remetem à socialização das condições da existência social, não podem prescindir do diálogo entre as ciências humanas e as "novas ciências" - por exemplo, a Psicologia Social -, e a informática, as quais permitem hoje a indexação da experiência coletiva dos recursos materiais e simbólicos absorvidos em sistemas autorregulados, como as redes sociais ${ }^{7}$. Através da ciência dos dados permitem a identificação de subjetividades e desejos dos seres humanos, para permitir a divulgação maciça de mensagens direcionadas, que tem por objetivo manipular a ação política em benefício de interesses privados.

Elas dão origem também às chamadas fake news, que, descoladas das necessidades históricas dos sujeitos sociais, produzem maciça desinformação, que não encontra correspondência na vida real. A abundância de meios de comunicação e o conjunto de discursos desvinculados da realidade produzem formas de ação política que fragmentam o tecido social, geram angústia e ampliam a violência.

Nossa pesquisa implicou a adoção dos seguintes procedimentos metodológicos:

\footnotetext{
${ }^{5}$ Souza e Moraes, 2012, p 52.

${ }^{6}$ Martins, 2005, p. 196; Ribeiro, 2011, p.38.

${ }^{7}$ Entrevista de Sergio Amadeu. Disponível em: <https://operamundi.uol.com.br/20-minutos/69472/20-minutossergio-amadeudefende-forte-regulacao-das-redes-sociais $>$.
} 
- produção de banco de dados a partir de informações da imprensa hegemônica e da imprensa contra-hegemônica, reunindo mais de 4.000 notícias;

- identificação dos atores, dos discursos e das ações dos integrantes das redes;

- aplicação da ferramenta Netvizz para a representação da macrorrede;

- exame da documentação apresentada na tabela "Nodes", disponibilizada pelo Facebook e derivada da aplicação da ferramenta Netvizz;

- decupagem dos campos que participam da rede bolsonarista;

- aplicação do programa "Worldclouds"8 para a formação das nuvens de palavras das categorias que compõem cada um dos campos; e

- representação da rede por grafos de atores e funções, mediante a utilização do programa GEPHI.

O ciberespaço constitui um novo espaço de interação social. Ele é composto por um conjunto de informações representado por novas técnicas simbólicas e intelectuais, nas quais a imagem constitui uma linguagem altamente expressiva da mensagem e dos caminhos de sua navegação. $\mathrm{O}$ advento da tecnologia digital ensejou a criação de formas espaciais que são, elas mesmas, objetos informacionais, corporificados por linguagens textuais e imagéticas. As tecnologias da imagem numérica alteram a constituição das formas espaciais, uma vez que inauguram novas formas de interação entre objetos, fluxos e ações, como define Milton Santos (1994).

Nessa perspectiva, cabe colocar, inicialmente, duas questões cruciais: quais são as formas específicas de comunicação e coesão social no espaço digital? Como se organizam os grupos sociais no ciberespaço?

As redes são formadas por diferentes grupos identitários, organizadas em nós (knots) e interconectadas pelas chamadas Tecnologias de Informação e Comunicação, as TICs. A informática define-as como $h u b s$, isto é, dispositivos físicos que conectam os atores de determinado grupo. Sua tarefa é receber a informação e a comunicação e transmiti-las aos demais membros do grupo. Cabe-nos aqui, portanto, examinar o conjunto de atores, assim como os vínculos, os fluxos de informação e comunicação existentes entre eles. Isso é fundamental para compreender como se associam para fazer a articulação da rede, a qual, a despeito de ser uma estrutura de interconexão instável no tempo e de aspecto dinâmico, pode e deve ser examinada e analisada. A realidade dos membros pode ser representada pela aplicação dos programas específicos de fluxos de comunicação e das ações políticas que a organizam ${ }^{9}$.

Essa pesquisa foi implementada logo após o primeiro turno do pleito de 2018, realizado no dia 7 de outubro, no qual Jair Bolsonaro recebeu $46 \%$ dos votos e Fernando Haddad $29 \%$.

A figura 1 representa a rede bolsonarista. Nele podemos visualizar tanto os atores quanto os processos de comunicação. Essa representação tornou-se possível graças à ferramenta Netvizz, então disponível no Facebook ${ }^{10}$. Nossa surpresa foi grande quando visualizamos, na página de

\footnotetext{
${ }^{8}$ Podemos traduzir por nuvem de palavras.

${ }^{9}$ Penna, 2007, p. 49.

${ }^{10}$ Essa ferramenta, que indicava a rede de seguidores de cada página, ainda estava disponível por ocasião do primeiro turno. Lamentavelmente, ela foi, em seguida, retirada da plataforma Facebook, impedindo, assim, a identificação dos grupos organizados por mediação de redes sociotecnicas no mundo. Vale denunciar aqui que essa prática do Facebook constituiu uma usurpação do direito à transparência do que acontece no ciberespaço.
} 
Bolsonaro, cerca de 11 milhões de seguidores e dez milhões de likes ${ }^{11}$, isto é, atos de comunicação.

Concomitantemente, foi gerada uma tabela denominada Nodes, que apresentava 858 páginas associadas à rede. A somatória de likes de cada página forma a totalidade da rede. Assim, quando somamos o número de likes de todas essas páginas, chegamos ao elevadíssimo número de 609.114.404 (seiscentos e nove milhões, cento e quatorze mil e quatrocentos e quatro) atos de comunicação. Sua importância está associada ao processo de atração que constitui as identidades coletivas. Metaforicamente, é uma nuvem que sobrevoa o território brasileiro e promove a atração de milhões de pessoas.

\section{Campos na análise da rede bolsonarista}

A tabela Nodes do Facebook permite-nos identificar não apenas os títulos das 858 páginas e o ID dos membros, mas também os setores nos quais atuam e o número de likes. Os títulos das páginas sugerem uma ideologia claramente de direita, por conseguinte contrária à esquerda, particularmente ao PT, e também à mídia em geral, às mulheres e à população LGBTS. Em contrapartida, pronunciam-se a favor da legalização de armas, do machismo, da violência e da morte, para citar apenas os sentidos mais relevantes.

Figura 1. Grafo da rede bolsonarista no Facebook

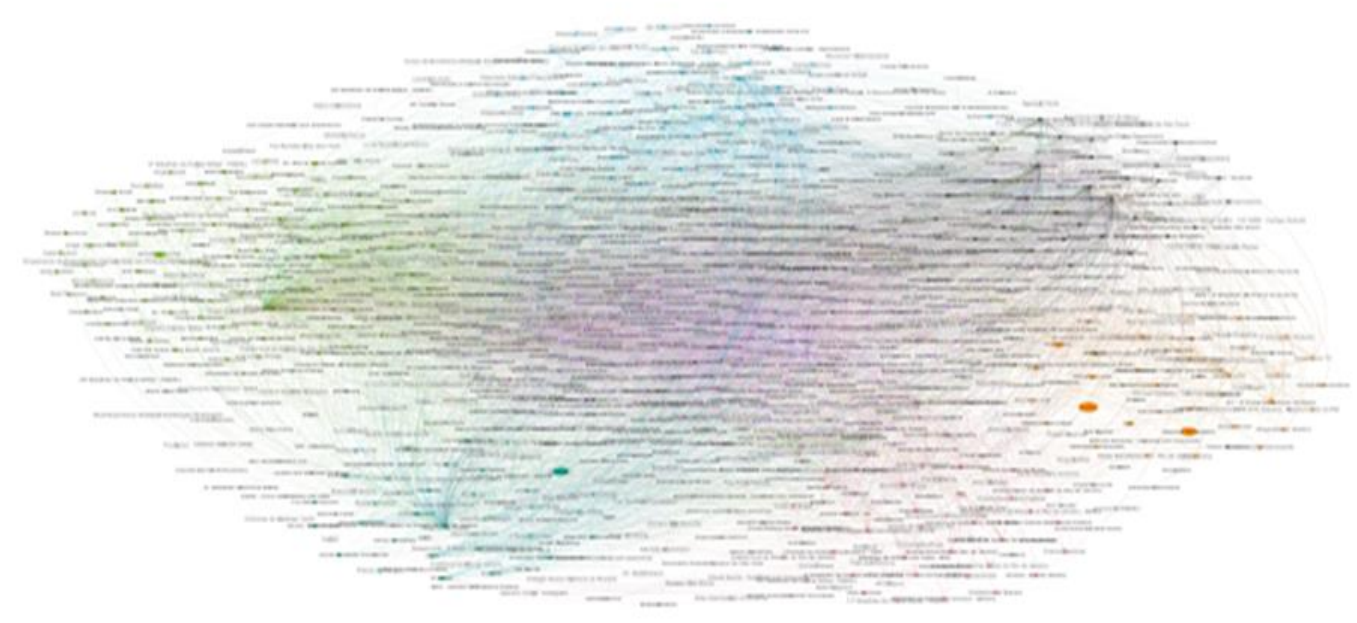

Fonte: elaboração própria a partir da ferramenta Netfizz disponível no Facebook, outubro 2018.

Para ampliar a visualização dos atores que participam dessa rede, optamos por representar o núcleo duro da rede, para tanto foi possível ler na tabela Nodes os vinte nomes principais, e os seus números de likes, sobre os quais aplicamos o programa GEPHI para desenhar na figura do grafo 2, a sua representação, o que nos permite identificar a importância desses atores na rede. Podemos ver os dados no quadro1 e figura 2 :

\footnotetext{
${ }^{11}$ Disponível em: <https://www.facebook.com/jairmessias.bolsonaro/>.
} 
Quadro 1. Núcleo duro da rede bolsonarista

\begin{tabular}{|c|c|c|}
\hline Nome & Curtidas & \% \\
\hline Netflix & 56.992 .228 & $18,34 \%$ \\
\hline National Geographic & 46.007 .101 & $14,80 \%$ \\
\hline History & 43.768 .437 & $14,08 \%$ \\
\hline Donald J. Trump & 23.941 .857 & $7,70 \%$ \\
\hline Fox News & 16.975 .860 & $5,46 \%$ \\
\hline Danilo Gentili & 12.886 .444 & $4,15 \%$ \\
\hline SBT & 11.476 .184 & $3,69 \%$ \\
\hline G1 - O Portal de Notícias da Globo & 10.660 .541 & $3,43 \%$ \\
\hline Mitt Romney & 9.810 .011 & $3,16 \%$ \\
\hline Senator Mitt Romney & 9.699 .222 & $3,12 \%$ \\
\hline Jair Messias Bolsonaro & 9.439 .296 & $3,04 \%$ \\
\hline The Economist & 8.944 .097 & $2,88 \%$ \\
\hline UOL & 8.186 .415 & $2,63 \%$ \\
\hline VEJA & 7.123 .747 & $2,29 \%$ \\
\hline The Wall Street Journal & 6.339 .146 & $2,04 \%$ \\
\hline Folha de S.Paulo & 5.804 .771 & $1,87 \%$ \\
\hline Dr. Ben \& Candy Carson & 5.781 .833 & $1,86 \%$ \\
\hline O Globo & 5.712 .607 & $1,84 \%$ \\
\hline Forbes & 5.672 .628 & $1,83 \%$ \\
\hline Total & 5.589 .465 & $1,80 \%$ \\
\hline Anderson 'The Spider' Silva & $\mathbf{3 1 0 . 8 1 1 . 8 9 0}$ & $\mathbf{1 0 0 , 0 0 \%}$ \\
\hline & & \\
\hline & & \\
\hline & &
\end{tabular}

Fonte: Parte do quadro Nodes disponível no Facebook, outubro 2018

Figura 2. Grafo do núcleo duro

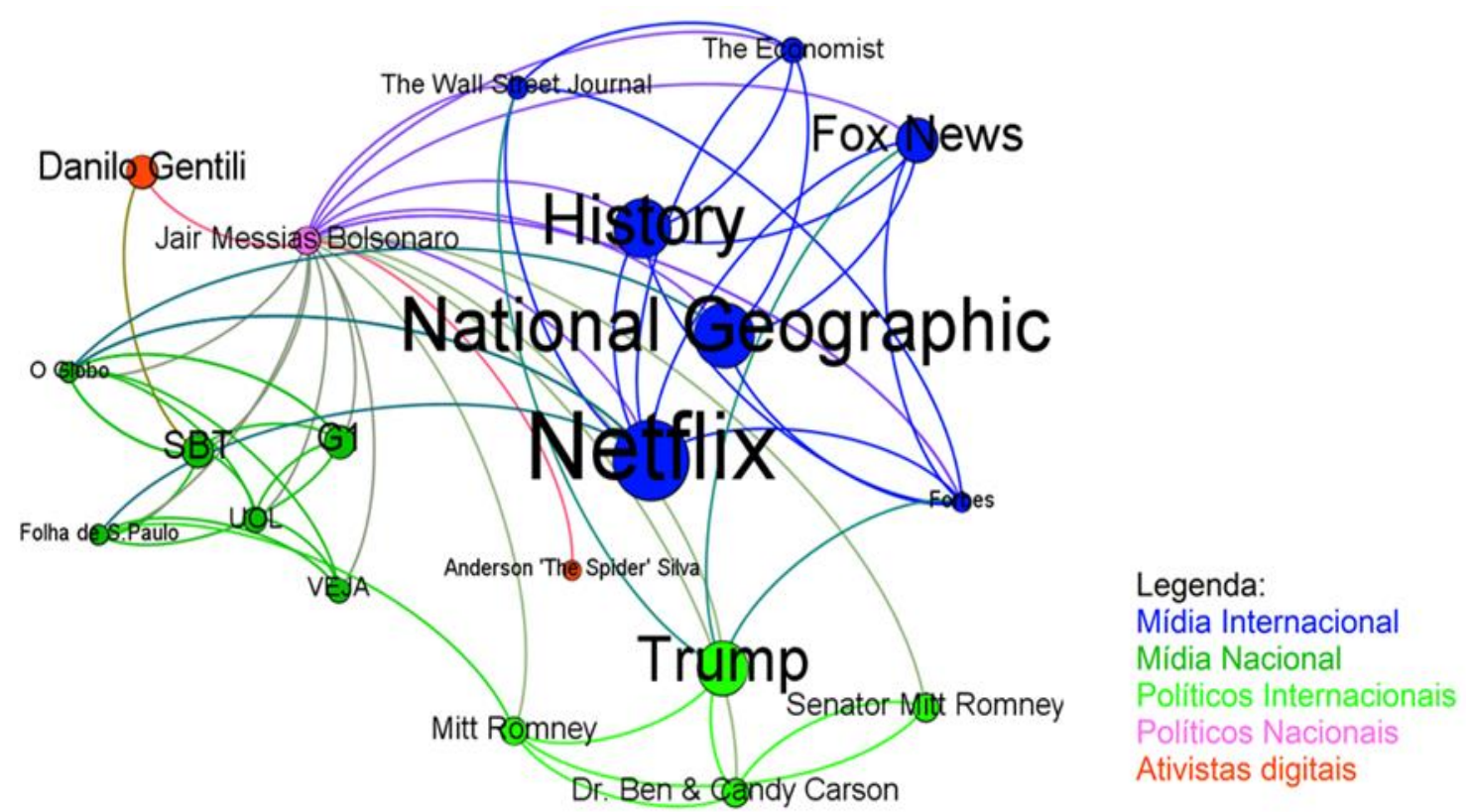

Fonte: Elaboração própria a partir da aplicação de dados primários do Facebook, junho de 2021 
Para fazer a leitura da rede é preciso saber que o tamanho da circunferência representa o número de likes dos atores, o que nos permite afirmar que National Geographic, Netflix e History, corporações americanas são as que dominam. Não menos importante é a presença de Donald Trump, seguido por Jair Bolsonaro. Na legenda podemos ler que participam desse núcleo duro, políticos ativistas digitais, associados a agentes nacionais e internacionais, que se articulam em rede, a partir de uma ideologia neoliberal, de direita conservadora e eleger Jair Bolsonaro, para a presidência da república do Brasil.

\section{Figura 3. Decomposição da rede bolsonarista em Campo}

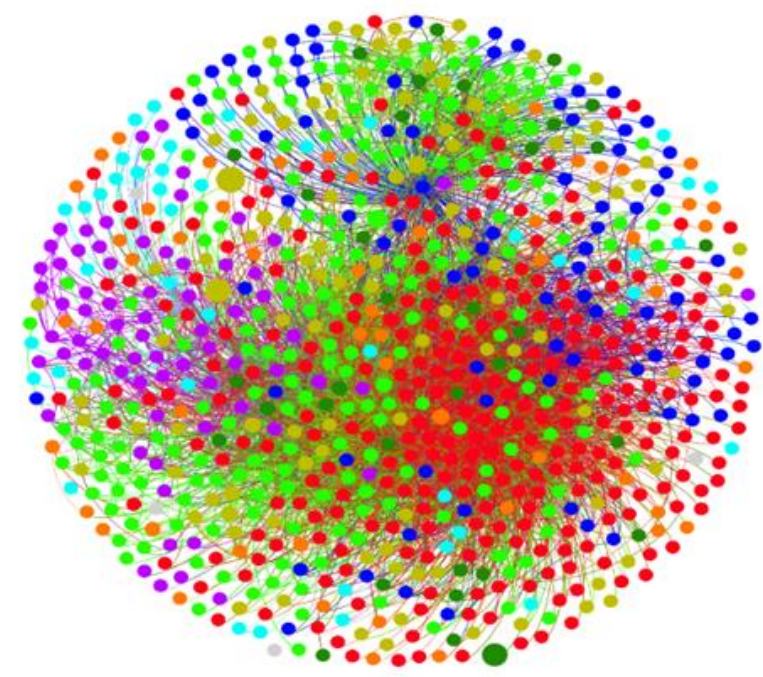

$\begin{array}{ll}\begin{array}{l}\text { Legenda } \\ \text { Campos }\end{array} \\ \square \text { Ativista digital } & (31,24 \%) \\ \square \text { Político } & (23,19 \%) \\ \square \text { Midia } & (12,24 \%) \\ \square \text { Ideológico } & (9,56 \%) \\ \square \text { Armado } & (8,04 \%) \\ \square \text { Cultura } & (6,29 \%) \\ \square \text { Capital } & (4,9 \%) \\ \square \text { Mídia Alternativa } & (3,96 \%) \\ \square \text { Outros } & (0,58 \%)\end{array}$

Fonte: Elaboração própria a partir da aplicação do programa Gephi, outubro, 2019.

A partir da verificação de cada uma das 858 páginas, identificamos oito campos que constam do Grafo 3, a saber:

1. ativista digital, que reúne um conjunto de atores que militam na web;

2. político, que congrega as páginas representativas dos atores do campo político propriamente dito;

3. mídia, formado pelos promotores e difusores da informação conservadora;

4. defesa e segurança, que inclui os militares e as instituições focadas na segurança pública;

5. ideológico, que abrange os chamados influenciadores que conferem ideologia à ação política bolsonarista;

6. cultural, no qual se concentram celebridades, artistas, instituições de cultura, entre outros;

7. capital, campo que compreende os agentes de todas as atividades econômicas;

8. mídia alternativa conservadora, constituído por blogs, youtubers e outros atores, todos associados a uma ideologia conservadora ${ }^{12}$.

\footnotetext{
${ }^{12}$ Vale mencionar que o nono campo é formado por um conjunto pequeno de seguidores, os Outros, os quais não conseguimos identificar.
} 
A existência de mais de 600 milhões de atos de comunicação dos seguidores exigia, evidentemente, uma análise sociológica. Mas como proceder a essa análise?

Recorremos à sociologia de Bourdieu (1998; 2004), que propõe analisar o espaço social mediante a aplicação da categoria "campo", formas de pensar, ser e agir compartilhadas, e da categoria "habitus", associada às práticas culturais no espaço. O título das páginas permitiu-nos levantar a identidade dos grupos e criar os campos, conforme proposto por Bourdieu (1998; 2004b).

Paralelamente, inserimos categorias em cada campo, o que nos permitiu fazer a síntese necessária para o desenvolvimento da análise. A conexão dos diferentes campos por fluxos de informação e comunicação digital configura a totalidade da rede bolsonarista. Como se trata de um ator político com existência concreta no espaço virtual e no vital, há que se efetuar uma análise capaz de dar conta dessa complexidade.

Começamos o nosso trabalho respondendo à pergunta sobre como o espaço social virtual da rede bolsonarista é formado. Era preciso ler e ver os grupos na sua existência virtual para compreender e analisar suas lutas simbólicas. Avançando na investigação, realizada a documentação dos atores e indicados os números de páginas e likes por campo, produzimos indicadores quantitativos e qualitativos. Pudemos, assim, identificar os sentidos das relações de comunicação compartilhados pelos atores dos campos, para usar a categoria de Bourdieu.

Examinamos essa totalidade mediante a leitura da Figura 4, que revela como os campos foram decupados. A teoria da Análise das Redes Sociais (ARS), retirada da ciência matemática, informa-nos que as posições no campo - conforme sua maior ou menor importância -, são definidas pelo número de atos de comunicação ${ }^{13}$. Para classificar essas redes, levamos em conta o número de atos de comunicação no intuito de conhecer a posição de cada um nelas. Isso revela o poder de difusão rizomática das narrativas fictícias veiculadas pela rede.

Reunindo quase 250 mil likes, o campo da mídia conservadora foi o mais acionado, seguido pelo campo político, com 161 mil. A participação da mídia alternativa também merece ser destacada. Chamou igualmente a nossa atenção o fato de o campo ideológico ter se revelado menos importante do que imaginávamos, somando apenas 35 mil likes.

\footnotetext{
${ }^{13}$ Penna, 2007, 49.
} 
Quadro 2. Campos da rede bolsonarista

\begin{tabular}{|c|c|c|c|c|}
\hline Campos & $\begin{array}{c}\text { Número de } \\
\text { páginas }\end{array}$ & $\begin{array}{c}\text { Porcentagem de } \\
\text { nós (\%) }\end{array}$ & Likes & $\begin{array}{c}\text { Porcentagem de } \\
\text { likes }(\%)\end{array}$ \\
\hline Mídia corporativa & 105 & 12,24 & 249.069 .607 & 40,89 \\
\hline Político & 199 & 23,19 & 160.916 .769 & 26,42 \\
\hline Mídia alternativa & 34 & 3,96 & 73.402 .349 & 12,05 \\
\hline Ativista digital & 268 & 31,24 & 35.364 .852 & 5,81 \\
\hline Cultura & 54 & 6,29 & 35.117 .305 & 5,77 \\
\hline Ideológico & 82 & 9,56 & 23.546 .641 & 3,87 \\
\hline Defesa e segurança & 69 & 8,04 & 23.525 .434 & 3,86 \\
\hline Capital & 42 & 4,90 & 5.370 .901 & 0,88 \\
\hline Outros & 5 & 0,58 & 2.800 .546 & 0,46 \\
\hline Total & $\mathbf{8 5 8}$ & $\mathbf{1 0 0 , 0 0}$ & $\mathbf{6 0 9 . 1 1 4 . 4 0 4}$ & $\mathbf{1 0 0 , 0 0}$ \\
\hline
\end{tabular}

Fonte: Elaboração própria a partir dos dados primários do Facebook, outubro de 2019.

Figura 4. Grafo da rede bolsonarista por campo

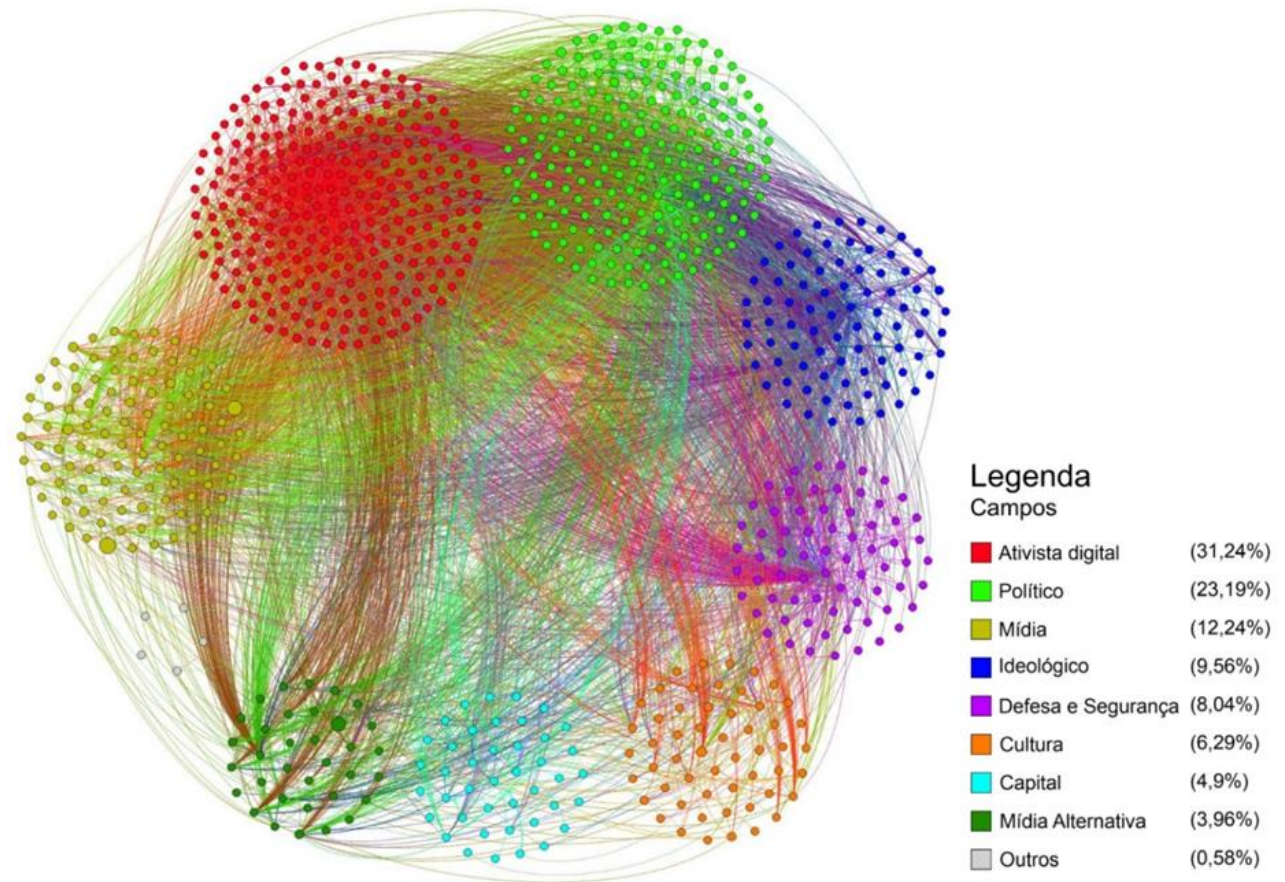

Fonte: Elaboração própria a partir dos dados primários do Facebook, outubro de 2018. 
Essa análise é importante porque apresenta a participação de cada campo na difusão de uma forma de pensar conservadora, que ignora os conhecimentos trazidos pela ciência e pela tecnologia, valoriza os fortes e exclui os fracos. Sua colocação em prática produz narrativas cotidianas contraditórias, que criam instabilidade política. Toda narrativa é uma estrutura simbólica que tem o poder de organizar o social ${ }^{14}$. Em outras palavras, a narrativa penetra no tecido social, sendo capaz de criar subjetividades que compartilham essa forma de pensar, ser e agir. Isso pode explicar as práticas do presidente Jair Bolsonaro, focadas na defesa da aprovação de sua rede de seguidores.

A figura 5, representa a totalidade da rede, revelada pelos filtros que dividem os campos. As redes estão desenhadas da esquerda para a direita e de cima para baixo, em ordem decrescente de importância. A relevância dessa decomposição reside no fato de ela nos orientar para a visualização da rede das redes. A representação de cada um dos campos decupados permitenos descobrir a posição ocupada por cada um deles nessa estrutura: quanto maior o número de atos de comunicação, maior a sua centralidade. Estamos lidando com um conjunto de agentes que se atraem por uma estrutura de valores e cria um sentido identitário compartilhado. São camadas de redes que se sobrepõem, umas sobre as outras e formam uma totalidade de alta complexidade.

Figura 5. Decupagem ${ }^{15}$ da rede por campo

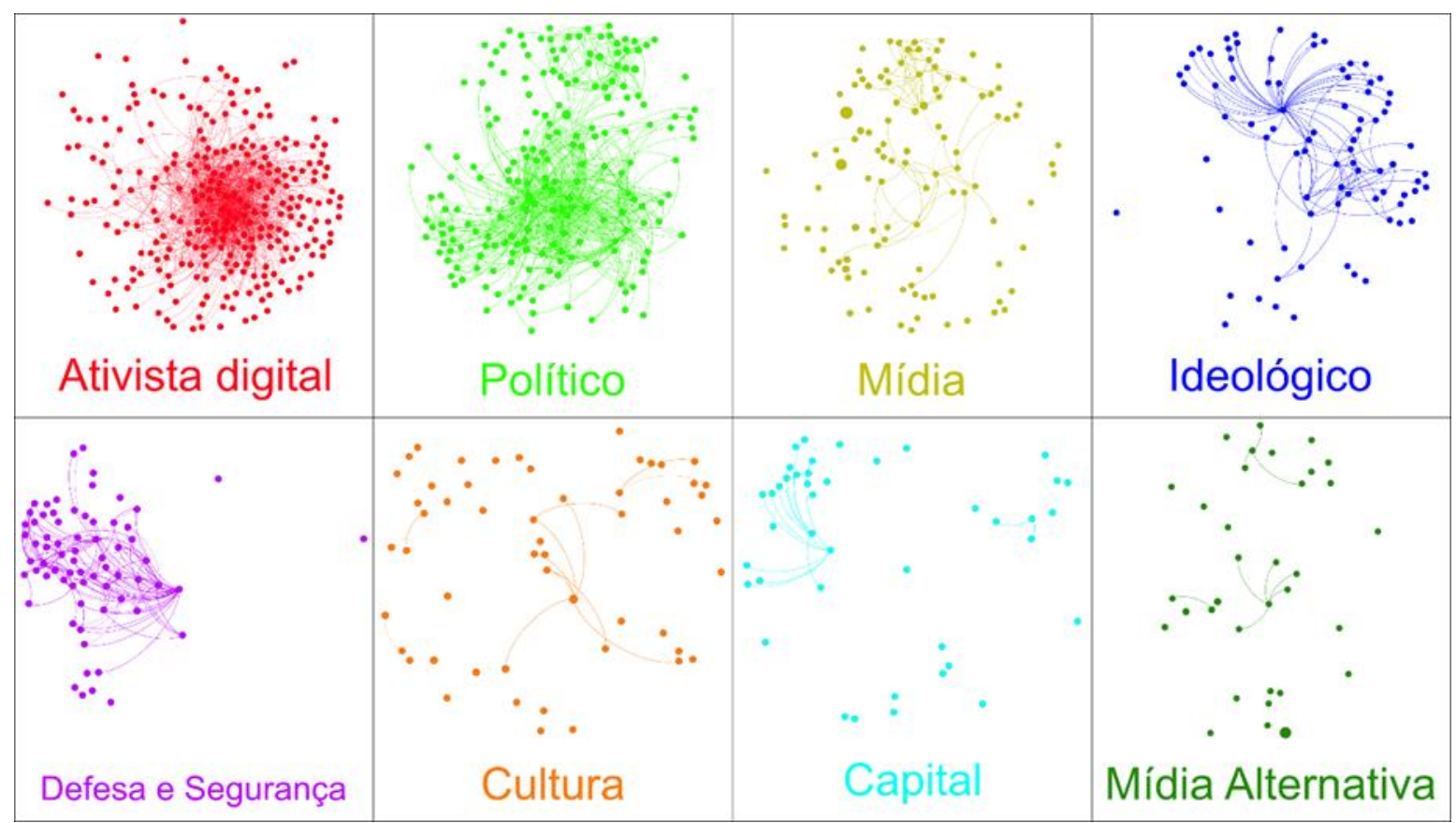

Fonte: Elaboração própria a partir dos dados primários do Facebook, outubro de 2018.

\footnotetext{
${ }^{14}$ Bourdieu, 1998, p. 4.

${ }^{15}$ Decupagem é uma palavra usada na edição de filmes e vídeos. Seu significado está associado ao corte que separa as partes de material filmado, para a seleção posterior que irá formar a totalidade. Usamos essa palavra para identificar as partes, ou melhor, os campos que formam a totalidade da macrorrede bolsonarista.
} 
A partir dessa decupagem foi possível produzir e definir os quadros, grafos e as nuvens de palavras que apresentamos na sequência. Os gráficos falam por si. Os agentes, ao criarem as páginas, atraíram muitos outros que compartilhavam o objetivo em comum de eleger Jair Bolsonaro; eles representam a coesão de todos que compõem a rede. Essa totalidade pode ser iluminada por Hanna Arendt (1994), que já havia percebido o significado de poder, lido pela capacidade de produzir o consenso de muitos atores, quanto a um curso comum da ação, o que confere aos seus membros de um coletivo o poder de agir em conjunto.

\section{Atores na tecnopolítica}

Para avançar na análise, partimos para o reconhecimento das categorias capazes de permitir o agrupamento das páginas e, com isso, obter a necessária síntese da totalidade. Assim, foram produzidos os dados para construir os respectivos quadros de categorias.

O quadro 3 permite-nos visualizar a centralidade dos ativistas digitais norte-americanos, o grupo mais poderoso, com mais de 16 milhões de likes, ou $46 \%$ das atividades de comunicação. Em seguida, temos a direita nacional, com $26,38 \%$. Fica claro aqui o compartilhamento de uma forma de pensar, ser e agir que unifica atores estrangeiros e brasileiros, associados por consenso e parceiros na atração de seguidores para uma forma de pensar calcada em valores tradicionais, neoliberais e politicamente autoritários.

Quadro 3. Categorias do campo Ativista Digital

\begin{tabular}{|c|c|c|c|c|}
\hline Categorias & $\begin{array}{c}\text { Número } \\
\text { de nós }\end{array}$ & $\begin{array}{c}\text { Porcentagem de } \\
\text { nós (\%) }\end{array}$ & Likes & $\begin{array}{c}\text { Porcentagem de } \\
\text { likes (\%) }\end{array}$ \\
\hline $\begin{array}{c}\text { Direita } \\
\text { internacional }\end{array}$ & 11 & 4,10 & 16.427 .956 & 46,45 \\
\hline Direita nacional & 24 & 8,96 & 9.327 .912 & 26,38 \\
\hline $\begin{array}{c}\text { Forças armadas e } \\
\text { segurança publica }\end{array}$ & 12 & 4,48 & 3.689 .183 & 10,43 \\
\hline Valores morais & 22 & 8,21 & 2.471 .502 & 6,99 \\
\hline Corrupção & 4 & 1,49 & 862.712 & 2,44 \\
\hline Outros & 195 & 72,76 & 2.585 .587 & 7,31 \\
\hline Total & $\mathbf{2 6 8}$ & $\mathbf{1 0 0 , 0 0}$ & $\mathbf{3 5 . 3 6 4 . 8 5 2}$ & $\mathbf{1 0 0 , 0 0}$ \\
\hline
\end{tabular}

Fonte: Elaboração própria a partir dos dados primários do Facebook, outubro de 2018.

Além dos dados quantitativos, tínhamos também por objetivo significar os sentidos das páginas do Facebook e, com isso, possibilitar as representações dominantes das identidades compartilhadas. Para isso, usamos o programa Worldclouds, que, ao representar os títulos e o tamanho das letras, torna possível observar a localização e o sentido dos atores que participam de cada campo.

A nuvem de palavras, que podemos ler na figura 6, apresenta as páginas mais importantes do Campo Ativista Digital. Para lê-la, devemos valorizar as cores e o tamanho das letras. Podemos assim visualizar, por exemplo, a página Tea Party Community, grupo que se opôs frontalmente a Barack Obama nas eleições de 2008 e 2012, e apoiou abertamente a candidatura de Donald Trump à presidência dos Estados Unidos no pleito de 2016. Uma das mais influentes organizações de direita nos Estados Unidos, The Heritage Foundation é um think tank 
conservador, que faz uma verdadeira apologia ao neoliberalismo, levando a liberdade individual e a redução da presença do Estado às últimas consequências.

Figura 6. Nuvem de Palavras. Campo Ativista Digital

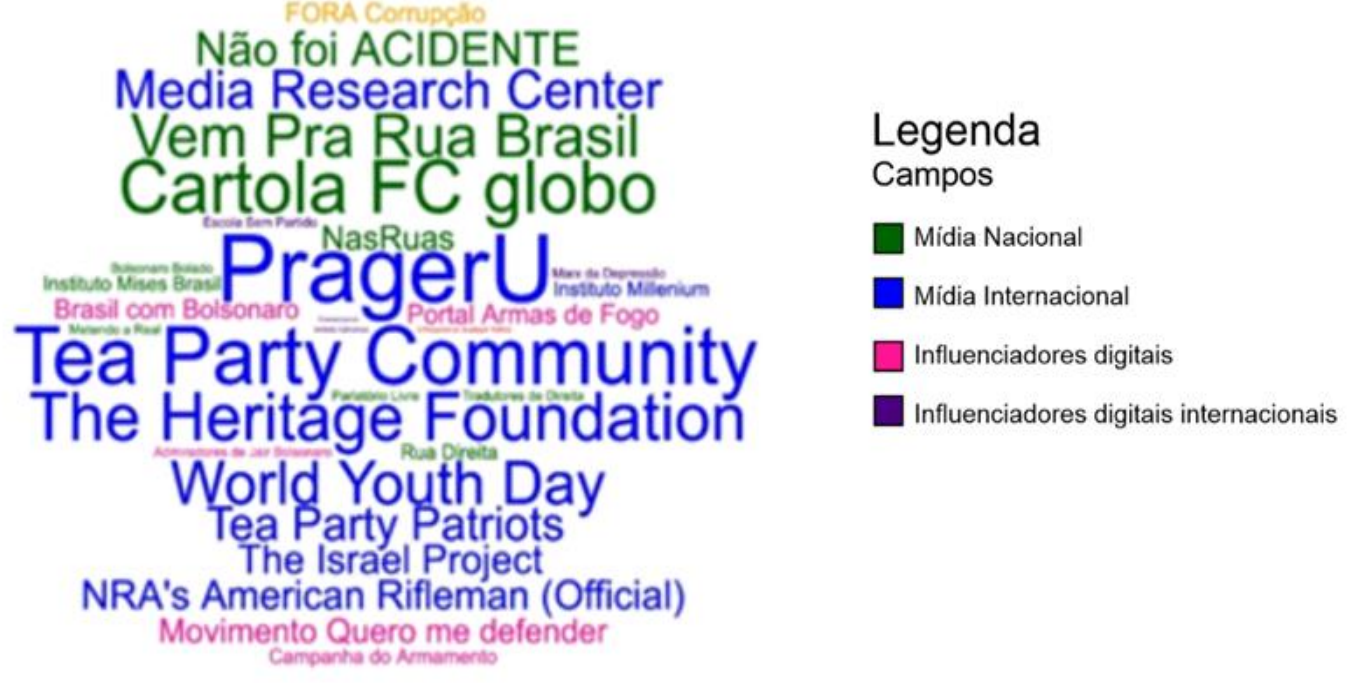

Fonte: Formulação própria aplicação da ferramenta Worldclouds no Campo Ativista Digital

Os grupos ativistas nacionais são os conhecidos "Vem Pra Rua Brasil", "Não foi acidente", "Fora Corrupção", "Nas ruas", "Quero me defender", "Portal das armas Brasil", "Campanha do armamento", "Com Bolsonaro". Eles fazem uma defesa incondicional da nacionalidade, explicitando uma mobilização política de direita, cujo fim último era a eleição de Jair Bolsonaro.

Tudo indica que a presença de organizações internacionais - leia-se, norte-americanas - foi de vital importância nas eleições de 2018, no Brasil. Atuando de forma coordenada, elas produziram o discurso que veio a embasar a política do governo Bolsonaro, caracterizada por uma ideologia neoliberal, lida na diminuição do papel do Estado, pela privatização/entrega do patrimônio público/natural em benefício de empresas estrangeiras e pela supressão das políticas sociais. As decisões do governo primam também pela tentativa de eliminação de todo pensamento divergente - mesmo que seja o da Rede Globo -, pela negação da ciência e da tecnologia, e pela individualização do corpo social.

As transversalidades entre as esferas política e religiosa e a transescalaridade que define a centralidade dos atores internacionais, aliadas ao seu poder de dominação em relação aos atores nacionais permitem-nos afirmar que a rede bolsonarista unifica, numa mesma totalidade, atores nacionais e internacionais, agentes políticos conservadores e igrejas pentecostais.

Em A praça e a torre, Niall Ferguson faz um balanço da importância das redes sociais em diferentes territórios e contextos históricos. O autor começa com as redes dos Illuminati. Surgidas no século XVII, elas recusavam todas as formas de dogmatismo, especialmente o das doutrinas políticas e religiosas tradicionais, e promoviam o livre pensamento, conferindo centralidade à ciência e à racionalidade crítica na filosofia. 
$\mathrm{Na}$ sequência, Ferguson examina as redes formadas nos territórios em que os banqueiros Rothschilds atuaram, no intuito de desvendar a sua estratégia de comunicação, voltada precipuamente para a conquista do poder político. Essa estratégia foi, em geral, bem-sucedida, na medida em que a velocidade da informação produzida permitia antecipar os fatos da conjuntura, muitas vezes antes dos governantes dos diferentes países. Outro exemplo que o autor examina foi o sistema de comunicação criado por Lênin, que formou uma importante rede de trabalhadores nas principais cidades russas partidários do ideário comunista ${ }^{16}$.

Na Alemanha do nacional-socialismo da década de 1930, fundado sobre a figura do líder carismático e que ganhou as roupagens de uma verdadeira religião política, permeado de liturgias simbólicas, a rede era centralmente organizada: abaixo do líder estavam os oficiais que trabalharam para o Führer; abaixo destes os líderes regionais, e a seguir, os chefes locais, e mais abaixo ainda, os líderes de células de bairro. No final da linha, havia em torno de 600 mil grupos de bairro, em torno da liderança de Adolf Hitler. Ao examinar a rede nazifascista na Alemanha, Ferguson demonstra como ela contribuiu decisivamente para a centralização do poder político e para a formação do Terceiro Reich ${ }^{17}$. Nessas redes, a comunicação era feita de forma autoritária, do líder para os súditos.

Um dos princípios da teoria das redes é a sua invisibilidade. Ao investigar as redes e suas hierarquias, Ferguson destaca como o seu poder é derivado dessa invisibilidade. Não é demais lembrar que os membros da rede bolsonarista alcançaram a vitória nas eleições de 2018, inclusive pelo fato de que ninguém percebera a sua presença.

As redes sempre existiram e sempre tiveram o poder de produzir transformações. Por isso, é crucial presentificar a sua existência, reconhecendo o peso decisivo das redes tecnopolíticas no campo político, as quais se situam além dos partidos políticos, sindicatos ou movimentos sociais. São elas sistemas técnicos que unificam diferentes campos e inauguram formas nunca antes imaginadas de ação política.

Essa transformação exige um avanço epistemológico capaz de reconhecer, entre outros atores políticos, os influenciadores da web, os movimentos sociais, as igrejas, organizações da sociedade civil e também das torcidas de futebol. Importa ter a coragem de examinar, e compreender, como atualmente a política é derivada da tecnopolítica, lendo-a como um ator político moldado pela inovação nas tecnologias de informação e comunicação ${ }^{18}$.

No quadro 4, que representa o campo político, nosso fio condutor da análise, separa-o em duas categorias, a dos atores políticos nacionais e a dos atores internacionais, estes últimos com uma presença mais significativa do que a dos primeiros.

\footnotetext{
${ }^{16}$ Ferguson, 2018, p. 258.

${ }^{17}$ Ferguson, 2018, p. 251.

${ }^{18}$ Empoli, 2020, p. 40.
} 
Quadro 4. Categorias do campo Político

\begin{tabular}{|c|c|c|}
\hline Políticos & Total & Porcentagem \\
\hline Nacional & 74.360 .727 & 47,03 \\
\hline Internacional & 83.741 .111 & 52,97 \\
\hline Total & $\mathbf{1 5 8 . 1 0 1 . 8 3 8}$ & $\mathbf{1 0 0 , 0 0}$ \\
\hline
\end{tabular}

Fonte: Elaboração própria a partir dos dados primários do Facebook, outubro de 2018.

Como podemos perceber na próxima nuvem de palavras (figura 7) o presidente Donald Trump ocupa a centralidade, exerce a hegemonia sobre a estrutura de poder local e explicita a soberania dos Estados Unidos sobre o Brasil. Ele é seguido pelo senador Mitt Romney, candidato do Partido Republicano à presidência dos EUA em 2012, derrotado por Barack Obama. Outro nome forte é o de Benjamin Solomon Carson, político estadunidense e intelectual negro, de direita, importante neurocirurgião pediátrico e membro da Igreja Adventista do Sétimo Dia. Filiado ao Partido Republicano, foi nomeado por Trump, secretário de Habitação e Desenvolvimento Urbano.

Figura 7. Nuvem de palavras. Campo Político

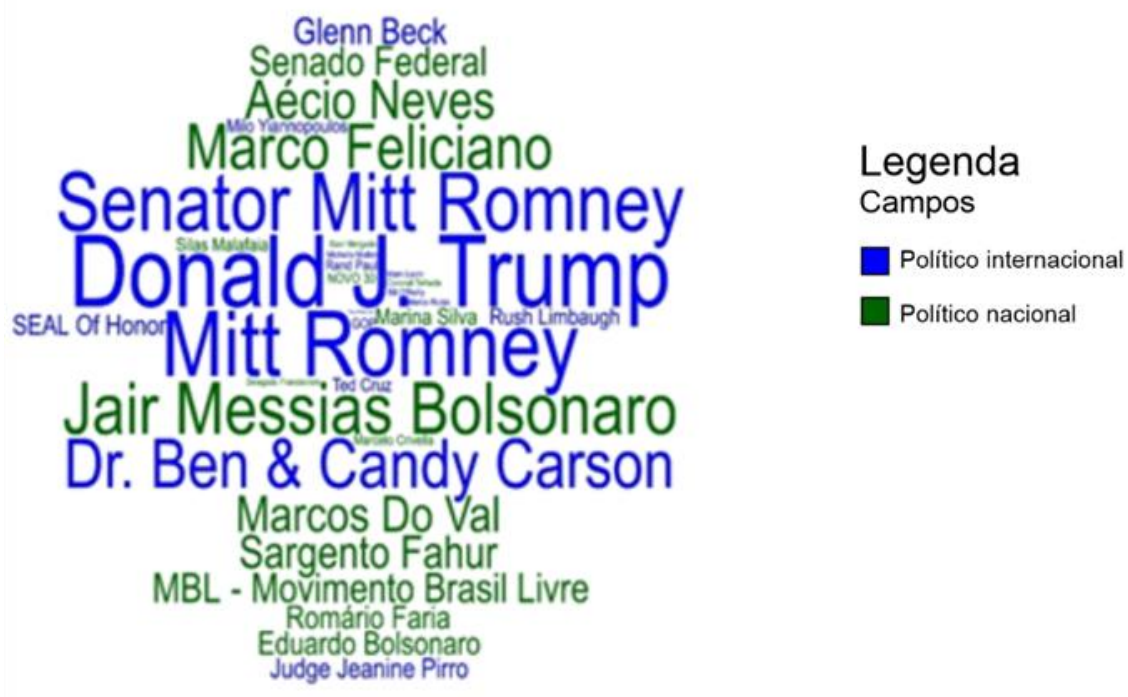

Fonte: Formulação própria aplicação da ferramenta Worldclouds no Campo Ativista Digital

A esses três nomes de políticos norte-americanos, seguem-se o do próprio Jair Bolsonaro, militar de extrema direita, de moral conservadora e eleito presidente do Brasil, e o de Marcos Feliciano - pastor da Catedral do Avivamento, uma igreja neopentecostal ligada à Assembleia de Deus - expulso do Partido Podemos, por infidelidade, quando apoiou a candidatura de Bolsonaro. Também marcam presença o conhecido Movimento Brasil Livre (MBL), movimento social de direita, o então senador Aécio Neves, principal liderança do impeachment da ex-presidente Dilma Rousseff; o ex-jogador de futebol Romário Faria, senador pelo Estado do Rio de Janeiro, o deputado federal Eduardo Bolsonaro, filho mais novo de Jair Bolsonaro e um dos principais artífices da formação da rede bolsonarista. 
Os dados levantados entre os dois turnos das eleições de 2018 permitem-nos afirmar, com toda segurança, que políticos nacionais e estrangeiros estavam mobilizados ativamente no apoio à candidatura de Bolsonaro. Essa disposição revela a clara interação entre diferentes atores no ciberespaço, que permite a transversalidade entre as escalas e esferas, integrando, numa mesma ação, políticos nacionais e internacionais, celebridades do mundo esportivo, movimentos sociais de direita e lideranças religiosas. Todos eles estão associados em torno de um objetivo compartilhado - a defesa do neoliberalismo econômico, de um ideário político de extrema direita e de valores morais tradicionais. Em outras palavras, funde interesses convergentes em rede tecnopolítca, formam uma totalidade complexa e inaugura formas de organização política pouco conhecidas na literatura.

Para examinar a participação de atores associados às instituições militares e de segurança, podemos ler no quadro 5, como sua presença na rede soma aproximadamente 23 milhões de likes, número não particularmente significativo por ocasião da eleição.

Nele se apresenta o número de páginas que atestam os atores que participam desse campo. Quase a metade do número de páginas é composta por instituições de segurança pública e pelas Forças Armadas, que reúnem membros do Exército, da Marinha e Aeronáutica. Os dados falam por si. Trata-se de um campo que exerce o poder instrumental de autorizar o porte de armas para o exercício da defesa do território e para a segurança pública do Brasil.

Quadro 5. Categorias do campo Defesa e Segurança

\begin{tabular}{|c|c|c|c|c|}
\hline Categorias & $\begin{array}{c}\text { Número de } \\
\text { páginas }\end{array}$ & $\begin{array}{c}\text { Porcentagem de } \\
\text { nós (\%) }\end{array}$ & Likes & $\begin{array}{c}\text { Porcentagem de } \\
\text { likes (\%) }\end{array}$ \\
\hline $\begin{array}{c}\text { Segurança } \\
\text { pública }\end{array}$ & 33 & 47,83 & 9.869 .155 & 41,95 \\
\hline Forças Armadas & 6 & 8,70 & 7.140 .860 & 30,35 \\
\hline Civis & 15 & 21,74 & 4.819 .140 & 20,48 \\
\hline $\begin{array}{c}\text { Polícia } \\
\text { internacional }\end{array}$ & 3 & 4,35 & 1.517 .474 & 6,45 \\
\hline Bombeiros & 3 & 4,35 & 134.507 & 0,57 \\
\hline Outros & 9 & 13,04 & 44.298 & 0,19 \\
\hline Total & $\mathbf{6 9}$ & $\mathbf{1 0 0 , 0 0}$ & $\mathbf{2 3 . 5 2 5 . 4 3 4}$ & $\mathbf{1 0 0 , 0 0}$ \\
\hline
\end{tabular}

Fonte: Elaboração a partir da tabela Nodes do Facebook, outubro 2018.

Esse campo foi formado pela identificação do seu habitus, formas de pensar, ser e agir relacionadas ao pertencimento a uma cultura, ideologia, rito, e também à cultura material compartilhada $^{19}$, unificando indivíduos que repartem uma estrutura de valores conservadora, associada às Forças Armadas. Contribuição fundamental de Bourdieu, essa categoria deve ser compreendida a partir dos processos de comunicação que integram os membros que participam do espaço social. Podemos aplicar essa categoria para examinar como se forma o habitus de um determinado campo, isto é, como o corpo do internauta se associa ao espaço social digital.

Havia, neste campo, posições favoráveis e contrárias à participação dos militares na política. Com o tempo, os generais foram sendo atraídos pelo discurso anti-PT e a maioria passou a fazer a defender a participação na política. Nessa altura, Jair Bolsonaro já era convidado a comparecer

\footnotetext{
${ }^{19}$ Bourdieu, 1998, p. 60; Boltansky, 2003, p. 155.
} 
às formaturas da Academia Militar das Agulhas Negras, onde fazia propaganda política. Foi então que começou a ser visto por alguns como um modelo, um mito.

Autores de reconhecida competência desse campo, denominado de bolsomilitarismo, afirmam peremptoriamente que os militares sempre advogaram não ter lado - seu dever é a defesa da pátria ${ }^{20}$. Entretanto, fatos mais recentes os desmentem. É notória a íntima associação das Forças Armadas à eleição de Bolsonaro e posteriormente ao seu governo. De acordo com o Tribunal de Contas da União (TCU), nada menos de 6.000 (seis mil) militares participam diretamente da atual administração ${ }^{21}$, não sendo demais relembrar que o vice-presidente, Hamilton Mourão, é militar. O principal objetivo do chamado partido bolsomilitar era voltar à política e participar discretamente do governo eleito, o que pode explicar o seu silêncio por ocasião do impeachment da presidente Dilma Rousseff e do julgamento e da condenação do ex-presidente Luís Inácio Lula da Silva.

Ao examinar as denominações das páginas na nuvem de palavras da figura 8, podemos observar os sentidos da ação política. "Eu nasci pra ser Polícia", "Esquadrilha da Fumaça", "Polícia no Sangue" revelam a identidade compartilhada do desejo de ser polícia. Com Vladimir Safatle (2018), aprendemos como as diferentes subjetividades são importantes na orientação da ação política, o que reafirma a importância dos afetos em Sigmund Freud. São eles que criam o sentido de atração e adesão a um determinado grupo social. A teoria freudiana estabelece as relações entre a condição psíquica e a emancipação social e para examiná-las Freud analisa a circulação social dos afetos, em especial das figuras paternas. Em outras palavras, ele trata das relações verticais, paternas e lideranças que instauram a integração social ${ }^{22}$.

Figura 8. Nuvem de palavras. Campo Defesa e Segurança

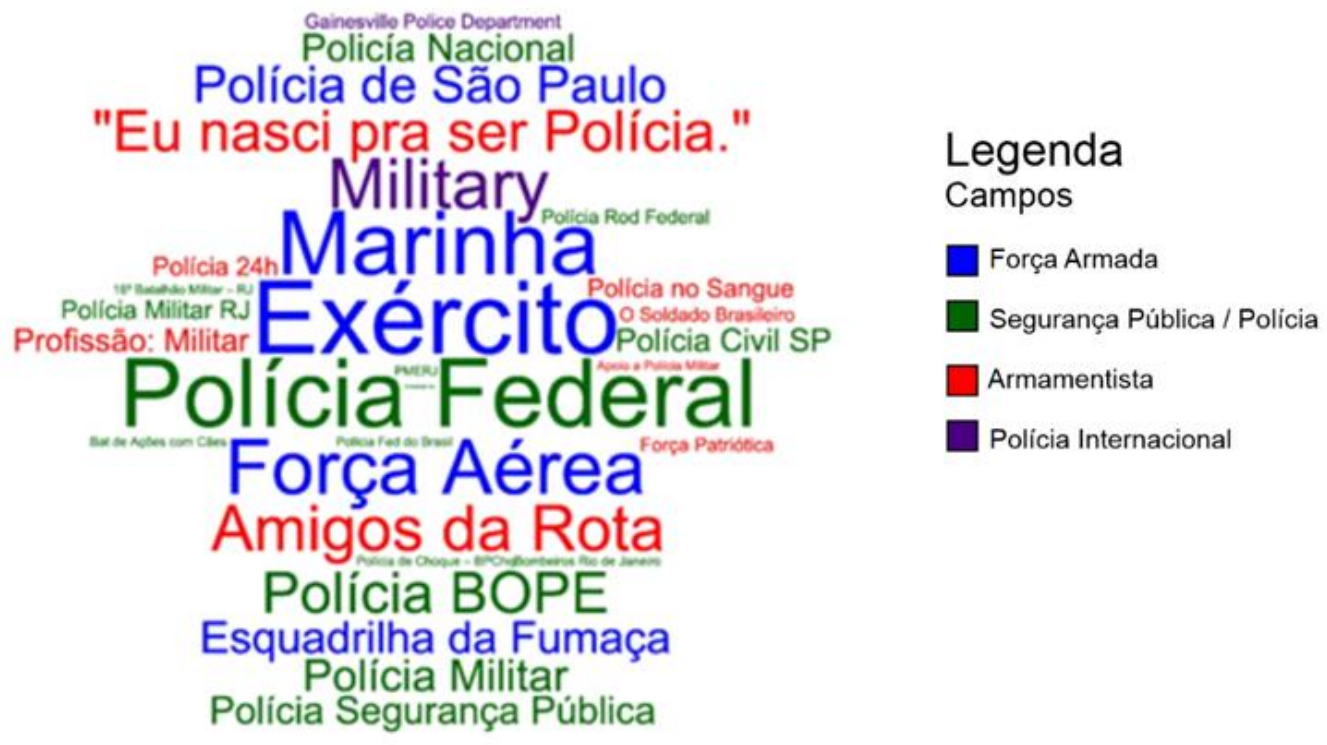

Fonte: Elaboração própria a partir dos dados primários do Facebook, outubro de 2018.

\footnotetext{
$20<$ https://valor.globo.com/politica/noticia/2020/06/16/militarizacao-nunca-saiu-do-horizonte-politico.ghtml>.

$21<$ https://g1.globo.com/politica/noticia/2020/07/17/governo-bolsonaro-tem-6157-militares-em-cargos-civisdiztcu.ghtml>.

${ }^{22}$ Safatle, 2018, p. 37.
} 
Os processos de identificação são fundamentais na vida social e não seria diferente na formação da integração do espaço vital, como não poderia ser diferente na rede do espaço virtual. A relação com o líder é uma variável de nossa análise que exige reflexão. Sabemos que a figura de Jair Bolsonaro está estreitamente associada à valorização do porte de armas, à exclusão social, à homofobia e à violência. Ao longo de toda a campanha presidencial, uma das imagens mais recorrentes mostrava-o com os dedos indicados como uma arma, apontando para a morte do outro. Uma identidade coercitiva atrai as outras e configura uma relação que faz emergir o poder constituinte de identidades coletivas. Queremos dizer com isso que o campo se constitui a partir da identificação de um coletivo com a liderança e resulta na formação de uma subjetividade violenta compartilhada.

Retomando Hanna Arendt (1994), a violência é instrumental e se manifesta pelo poder das armas. Trata-se de uma política de mortalidade, associada ao poder de um contra todos, entendendo o poder como a capacidade que os homens têm de agir em conjunto. Isso, por sua vez, requer o consenso de muitos quanto a um curso comum da ação. A política exige um estar ligado aos outros, quando os homens se movem juntos e formam um coletivo. Exige compreender o outro em sua própria identidade, exige reconhecer a alteridade. $\mathrm{O}$ poder necessita de um número de pessoas e da violência de armas que não reconhece o direito à diferença. A democracia é o exercício do poder de muitos em consenso, ao passo que o autoritarismo é o exercício da violência pela posse de armas.

As categorias criadas no campo da grande mídia (quadro 6), revelam a presença destacada da mídia internacional - mais de $60 \%$ dos likes -, secundada pela mídia nacional, com $27 \%$. O levantamento dos dados mostra a Netflix na liderança em número de seguidores e a sua centralidade pode ser reconhecida pelos quase 67 milhões de likes, seguida pela National Geographic, com 46 milhões. Já a mídia nacional tem à frente o SBT, seguido da Rede Globo, da Folha de S. Paulo e da revista Forbes.

Quadro 6. Categorias do campo Mídia

\begin{tabular}{|c|c|c|c|c|}
\hline Categorias & $\begin{array}{c}\text { Número } \\
\text { de nós }\end{array}$ & $\begin{array}{c}\text { Porcentagem de } \\
\text { nós (\%) }\end{array}$ & Likes & $\begin{array}{c}\text { Porcentagem de } \\
\text { likes (\%) }\end{array}$ \\
\hline Mídia internacional & 18 & $17,31 \%$ & 142.773 .314 & $61,50 \%$ \\
\hline Mídia nacional & 35 & $33,65 \%$ & 62.624 .322 & $26,98 \%$ \\
\hline $\begin{array}{c}\text { Influenciadores de Direita } \\
\text { nacional }\end{array}$ & 12 & $11,54 \%$ & 19.657 .885 & $8,47 \%$ \\
\hline $\begin{array}{c}\text { Influenciadores de Direita } \\
\text { internacional }\end{array}$ & 5 & $4,81 \%$ & 6.237 .846 & $2,69 \%$ \\
\hline Outros & 34 & $32,69 \%$ & 840.380 & $0,36 \%$ \\
\hline Total & $\mathbf{1 0 4}$ & $\mathbf{1 0 0 , 0 0}$ & $\mathbf{2 3 2 . 0 9 3 . 7 4 7}$ & $\mathbf{1 0 0 , 0 0}$ \\
\hline
\end{tabular}

Fonte: Elaboração a partir da tabela Nodes do Facebook; outubro 2018. 
As grandes mídias, que participaram ativamente no impeachment da então presidente Dilma Rousseff e no julgamento e na prisão do ex-presidente Luiz Ignácio Lula da Silva Lula, estiveram estreitamente associadas ao movimento que elegeu Jair Bolsonaro. Elas foram capazes de engendrar um discurso acusatório e a construir um consenso em torno da luta contra a corrupção, o que legitimou o desmonte e a manipulação da democracia no Brasil ${ }^{23}$.

Como podemos ler nas nuvens de palavras da figura 9, a cor azul e o tamanho das letras atestam a participação decisiva das grandes corporações da imprensa dos Estados Unidos. Esse conjunto reúne em torno de 142 milhões de likes. Merecem menção especial a Netflix, que promove o habitus da cultura norte-americana e a valorização do modo de vida do país, contribuindo para a sua reprodução em outras partes do mundo, e o National Geographic, associado à indústria do turismo e responsável pela publicação de belas fotografias no Google, difundindo as belezas naturais e os registros históricos do planeta. Seguem-lhe a mídia nacional, com mais de 60 milhões de likes, que inclui, além dos veículos já mencionados, o jornal carioca $O$ Globo e as revistas Superinteressante e Isto é.

Figura 9. Nuvem de palavras. Campo das Corporações de Mídia

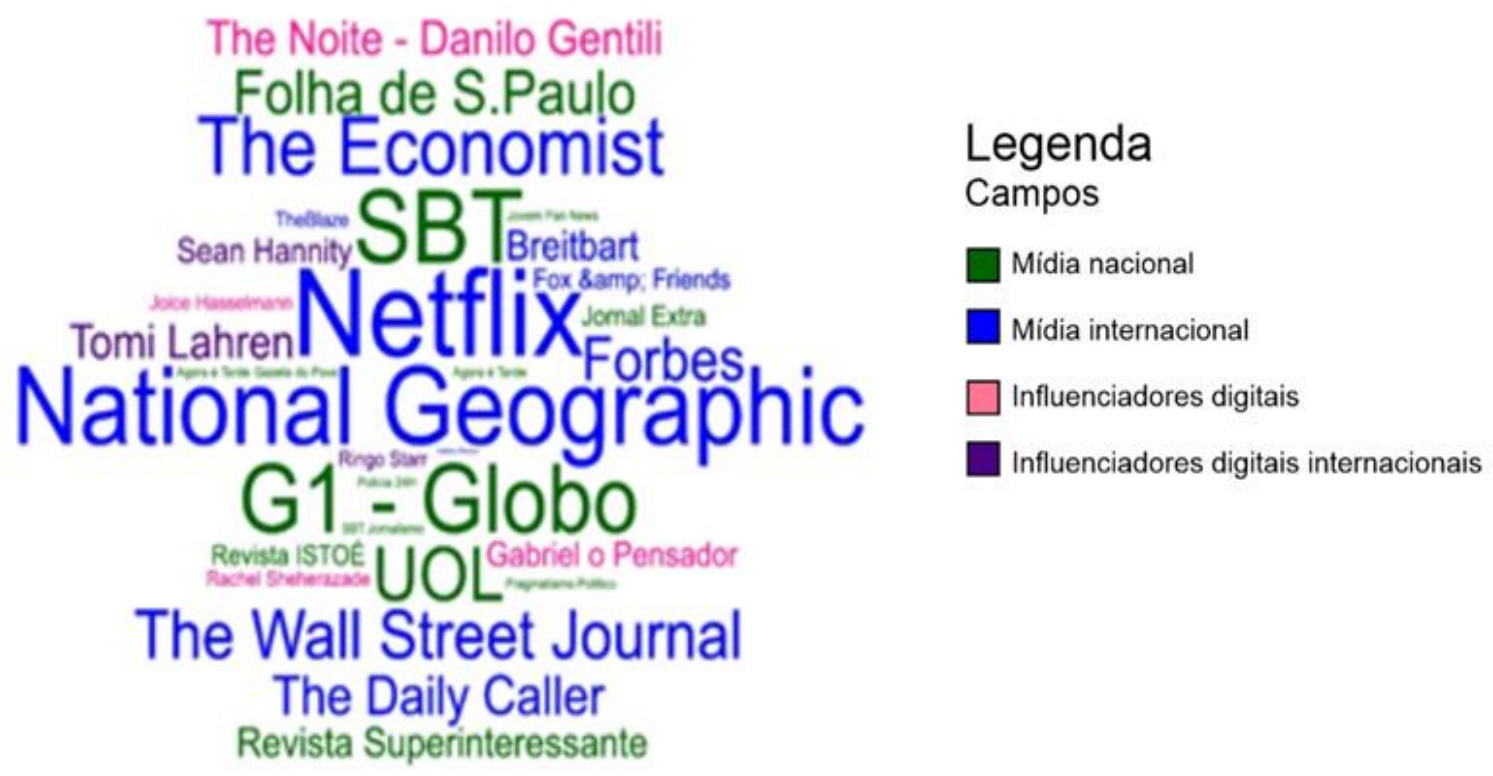

Fonte: Formulação própria aplicação da ferramenta Worldclouds no Campo Ativista Digital.

A centralidade do capital nacional (quadro 7), é aqui representada por empresas da indústria de alimentos, como a Kopenhagen, a Ambev e a Barilla, que respondem por cerca de $60 \%$ de comunicação. Sempre atentas ao projeto econômico neoliberal, de privatização da esfera pública, elas impulsionaram a candidatura de Jair Bolsonaro quando financiaram os ataques cibernéticos $^{24}$. Como sabemos o Facebook, permite a impulsão de mensagens pagas em

\footnotetext{
${ }^{23}$ Castells, 2018, p. 37; Chomsky, 2017, p. 21.

24 Estamos cientes de que não constam dessa rede do Facebook empresários conhecidos, que apoiaram abertamente a candidatura de Bolsonaro, entre os quais João Apollinário - Polishop; Sebastião Bomfim Centauro; Afrânio Nogueira - Coco Bambu; Cristiana Arcangeli - dona de empresas na área de alimentação e beleza; Luciano Hang - o proprietário da cadeia de lojas de departamentos Havan; Gabriel Rocha Kenner presidente do grupo "Brasil 200"; Flávio Rocha - dono das lojas Richuelo ; Madero Junior Durski - dono da rede de restaurantes "Madero"; Otavio Fakhoury - que se apresenta como "investidor"; Edgard Corona - Bio Ritmo;
} 
grandes quantidades, e essas mensagens viabilizam uma ampla circulação de narrativas fictícias através dessa organização. A impulsão paga diretamente pelo capital ao Facebook ajuda a explicar os baixos custos da campanha bolsonarista.

\section{Quadro 7. Campo do Capital}

\begin{tabular}{|c|c|c|c|c|}
\hline Categorias & $\begin{array}{c}\text { Número de } \\
\text { nós }\end{array}$ & $\begin{array}{c}\text { Porcentagem } \\
\text { de nós }\end{array}$ & Likes & $\begin{array}{c}\text { Porcentagem de } \\
\text { Likes }\end{array}$ \\
\hline Capital Nacional & 6 & $13,95 \%$ & 4998330 & $61,85 \%$ \\
\hline $\begin{array}{c}\text { Armamentista } \\
\text { Internacional }\end{array}$ & 3 & $6,98 \%$ & 1461165 & $18,08 \%$ \\
\hline Moda & 5 & $11,63 \%$ & 432313 & $5,35 \%$ \\
\hline Capital Internacional & 8 & $18,60 \%$ & 422158 & $5,22 \%$ \\
\hline Imobiliário & 1 & $2,33 \%$ & 229130 & $2,84 \%$ \\
\hline Armamentista Nacional & 3 & $6,98 \%$ & 218060 & $2,70 \%$ \\
\hline Outros & 15 & $34,88 \%$ & 195577 & $2,42 \%$ \\
\hline Influenciadores & 2 & $4,65 \%$ & 124145 & $1,54 \%$ \\
\hline Total & $\mathbf{4 3}$ & $\mathbf{1 0 0 , 0 0}$ & $\mathbf{8 0 8 0 8 7 8}$ & $\mathbf{1 0 0 , 0 0}$ \\
\hline
\end{tabular}

Fonte: Elaboração a partir da tabela Nodes do Facebook, outubro 2018

O capital armamentista participa do vetor de atração, por intermédio das norte-americanas Black SKull USA e da Haley Strategic Partner USA ${ }^{25}$, e das fabricantes nacionais Taurus Armas e Vista Direita, conforme revela a Figura. Elas e outros atores menos importantes são responsáveis por aproximadamente $25 \%$ dos atos de comunicação desse campo. Isso facilita a compreensão da obsessão do presidente pelas armas, quer como candidato - quando o símbolo principal eram seus dedos apontados -, quer já como presidente, quando assinou decretos para facilitar a aquisição de armas.

Marcelo Pessoa - Galápagos Capital Gestora de Fundos; Washington Cine - Gocil, citados em Portal Brasil 247 <https://www.brasil247.com/brasil/empresarios-bolsonaristas-colhem-uma-economia-em-frangalhos-e-podemsofrer-boicotes $>$.

${ }^{25}$ HuffPost Brasil <https://www.huffpostbrasil.com/entry/1-ano-decretoarmas_br_5e1f57b6c5b673621f6f73ae>. 
Figura 10. Nuvem de palavras. Campo do Capital

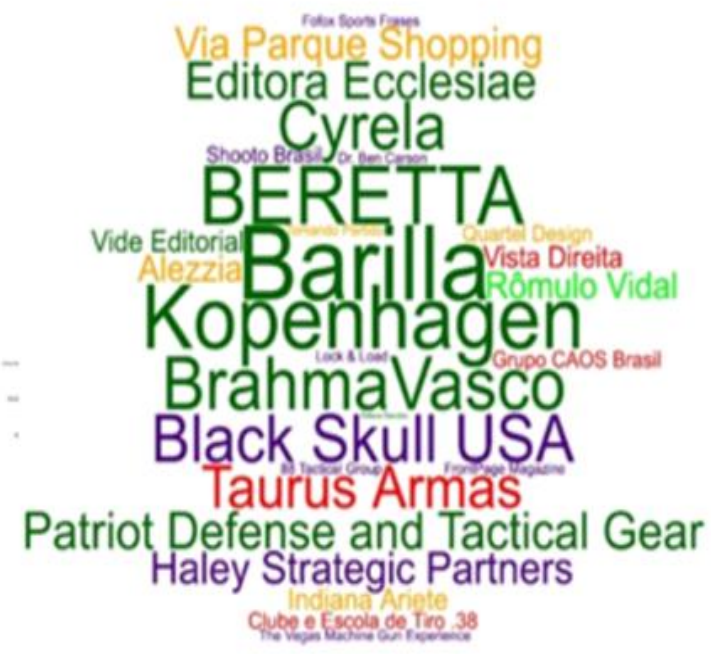

Legenda

Campos

Armamentista internacional

Capital Nacional

Armamentista nacional

Capital internacional

Moda

Influenciadores

Fonte: Formulação própria aplicação da ferramenta Worldclouds no Campo Ativista Digital

Entre janeiro de 2019 e abril de 2020, a Casa Civil e os ministérios da Defesa, da Justiça e das Relações Exteriores abriram espaço em suas agendas oficiais para 73 audiências e reuniões com lobistas e empresários do setor de armas e munições. Pelo menos 16 desses encontros oficialmente registrados ocorreram em semanas em que o governo publicou portarias e decretos para atender às demandas de representantes dessas empresas ${ }^{26}$, prova inconteste do grande interesse por parte da indústria armamentista, nacional e internacional, em eleger Jair Bolsonaro.

Essa dimensão dá conta apenas do aspecto econômico. Não menos importante é a permanente violência que marca sua subjetividade. O discurso de Jair Bolsonaro reúne, entre outros ingredientes, ataques constantes às instituições democráticas, indiferença pelo outro, veiculações cotidianas de mentiras, misturados com forte autoritarismo, crueldade para com os diferentes e onipotência destrutiva em relação a seus oponentes. A manipulação de dados e informações que fluem pela rede na disseminação de fake news tem por objetivo criar uma realidade fictícia ${ }^{27}$ que lhe permite transformar as pessoas em objetos de sua perversão e de sua necropolitica, "na morte dos corpos humanos e das populações"28.

\section{A rede de Fernando Haddad}

No intuito de estabelecer uma comparação com a rede bolsonarista, a pesquisa também examinou a formação da rede sociotécnica do candidato petista Fernando Haddad, no Facebook. Seguimos os mesmos passos. Assim, após a aplicação da ferramenta Netifiz, identificamos aproximadamente um milhão de seguidores, que organizamos em três campos, o político, o

\footnotetext{
${ }^{26}<$ https://brasil.estadao.com.br/blogs/estadao-podcasts/noticia-no-seu-tempo-lobistas-de-armas-tiveram-pelomenos-73-audiencias-no-governo-interior-supera-capital-em-casos-de-covid-e-um-concerto-para-plantas-embarcelona/s.

${ }^{27}$ Kakutani, 2018.p 12.

${ }^{28}$ Mbembe, 2018, p. 80.
} 
cultural e um terceiro, reunindo outros menos importantes. O quadro 8 apresenta a divisão por campo e o número de seguidores.

Quadro 8. Campos da rede Haddad

\begin{tabular}{|c|c|c|c|c|}
\hline Campos & $\begin{array}{c}\text { Número de } \\
\text { nós }\end{array}$ & $\begin{array}{c}\text { Porcentagem } \\
\text { de nós }\end{array}$ & Likes & $\begin{array}{c}\text { Porcentagem } \\
\text { de Likes }\end{array}$ \\
\hline Agentes Culturais & 94 & $48,21 \%$ & 1514929 & $27,07 \%$ \\
\hline Agentes Governamentais & 80 & $41,03 \%$ & 3683259 & $65,81 \%$ \\
\hline Outros & 21 & $10,77 \%$ & 398211 & $7,12 \%$ \\
\hline Total & $\mathbf{1 9 5}$ & $\mathbf{1 0 0 , 0 0 \%}$ & $\mathbf{5 5 9 6 3 9 9}$ & $\mathbf{1 0 0 , 0 0 \%}$ \\
\hline
\end{tabular}

Fonte: Elaboração própria a partir dos dados primários do Facebook, outubro de 2018.

A separação nos três campos foi realizada a partir da leitura da tabela Nodes, onde estavam indicados os nomes das páginas. Como podemos ler no quadro 8 , o primeiro campo compreende as agências governamentais, com $65 \%$ do total; no segundo encontram-se os agentes/programas culturais, com 27\%; e no terceiro, o do Outros, os atores de menor relevância, com 7,00 \%, soma uma totalidade de 550.000 likes. Essa rede, formada no território da cidade de São Paulo, reproduz as relações vitais da gestão de Haddad à frente da prefeitura paulistana, entre 2013 e 2016. Essa rede, centralmente organizada, reúne instituições governamentais que oferecem atividades burocráticas e culturais à população de São Paulo (Figuras 11 e 12). Trata-se, tão somente, de uma reprodução das relações vitais, que desconhece a dinâmica das relações virtuais.

Figura 11. Divisão dos campos na rede Haddad

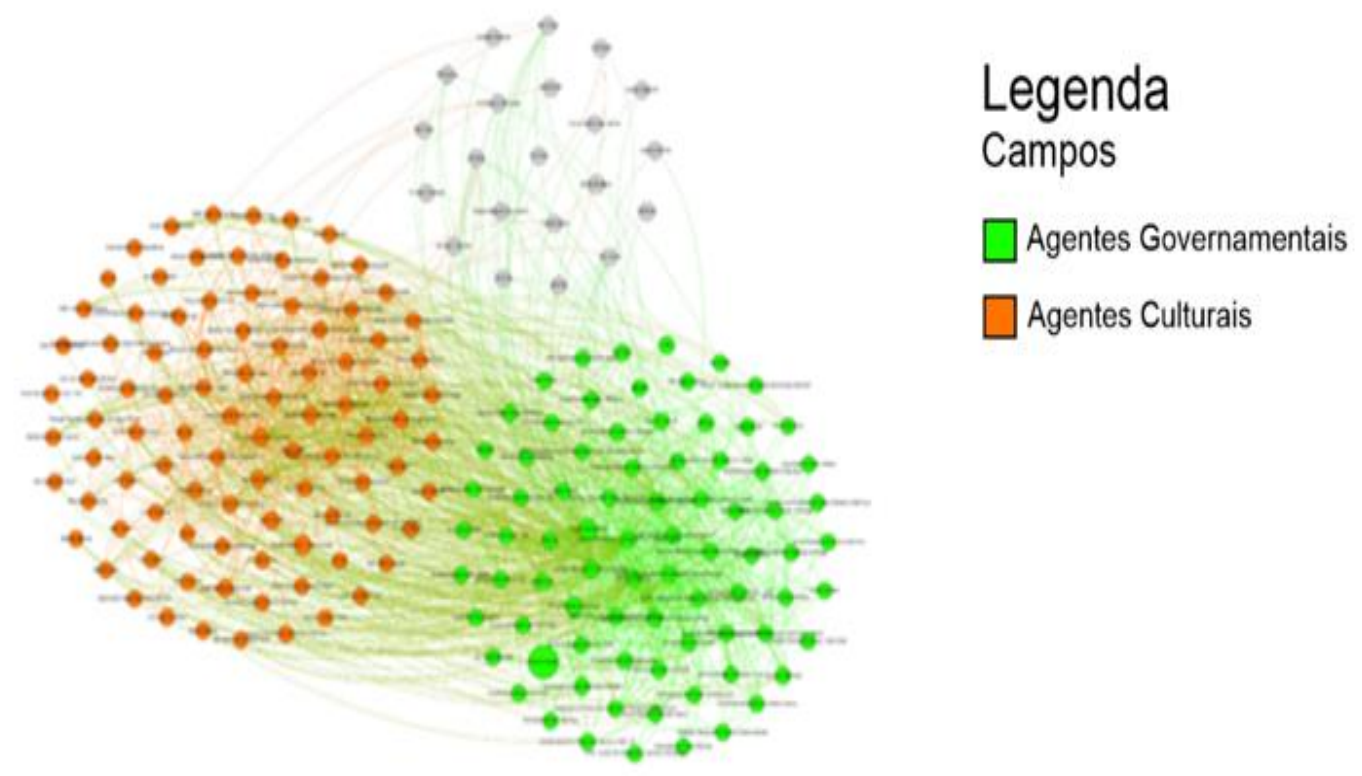

Fonte: Elaboração própria a partir dos dados primários do Facebook, outubro de 2018. 
Figura 12. Decupagem da rede por campos

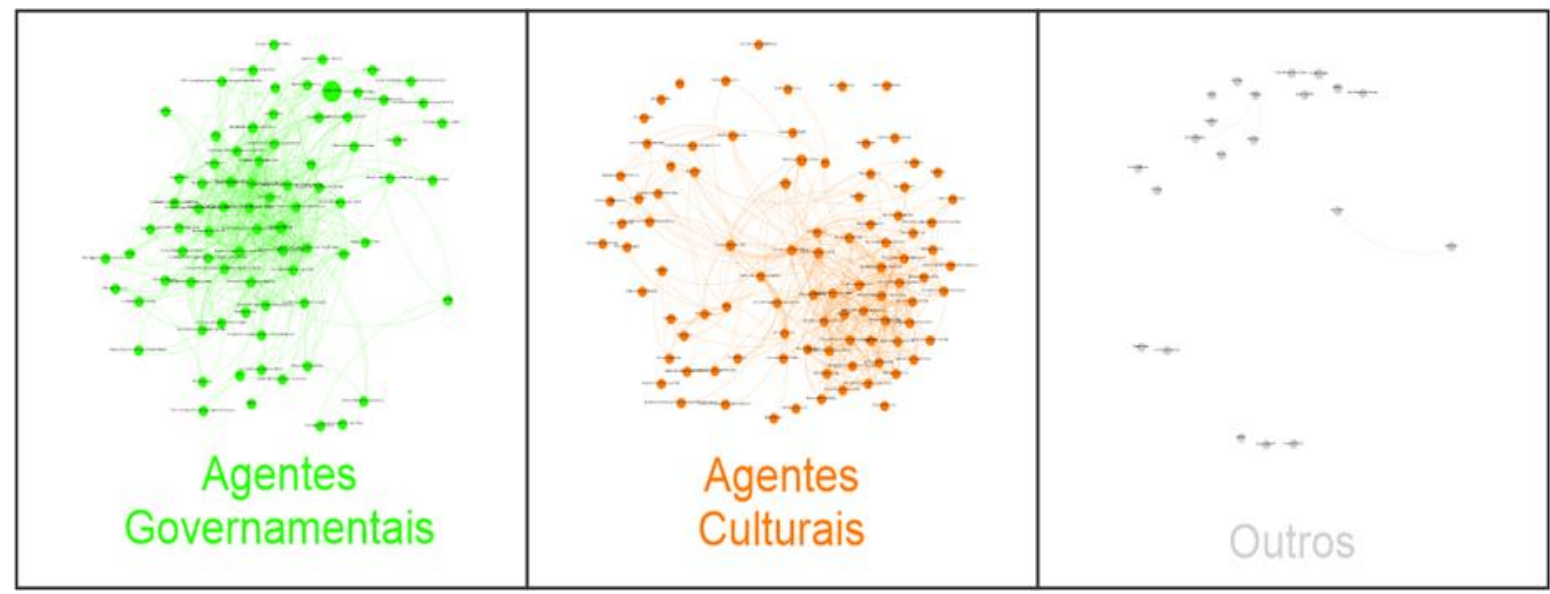

Fonte: Elaboração própria a partir dos dados primários do Facebook, outubro de 2018.

A partir dessa decoupagem (figuras 11 e 12), foi possível produzir as nuvens de palavras, apresentadas. No campo governamental, identificamos as organizações que fazem parte da prefeitura de São Paulo; na centralidade da rede, reconhecemos a presença de Fernando Haddad, o prefeito, em segundo plano a da Câmara Municipal, e em seguida a das secretarias municipais,_destacando-se no conjunto a Secretaria de Educação (Figura 13).

Figura 13. Nuvem de palavras. Campo das agências governamentais da rede Haddad

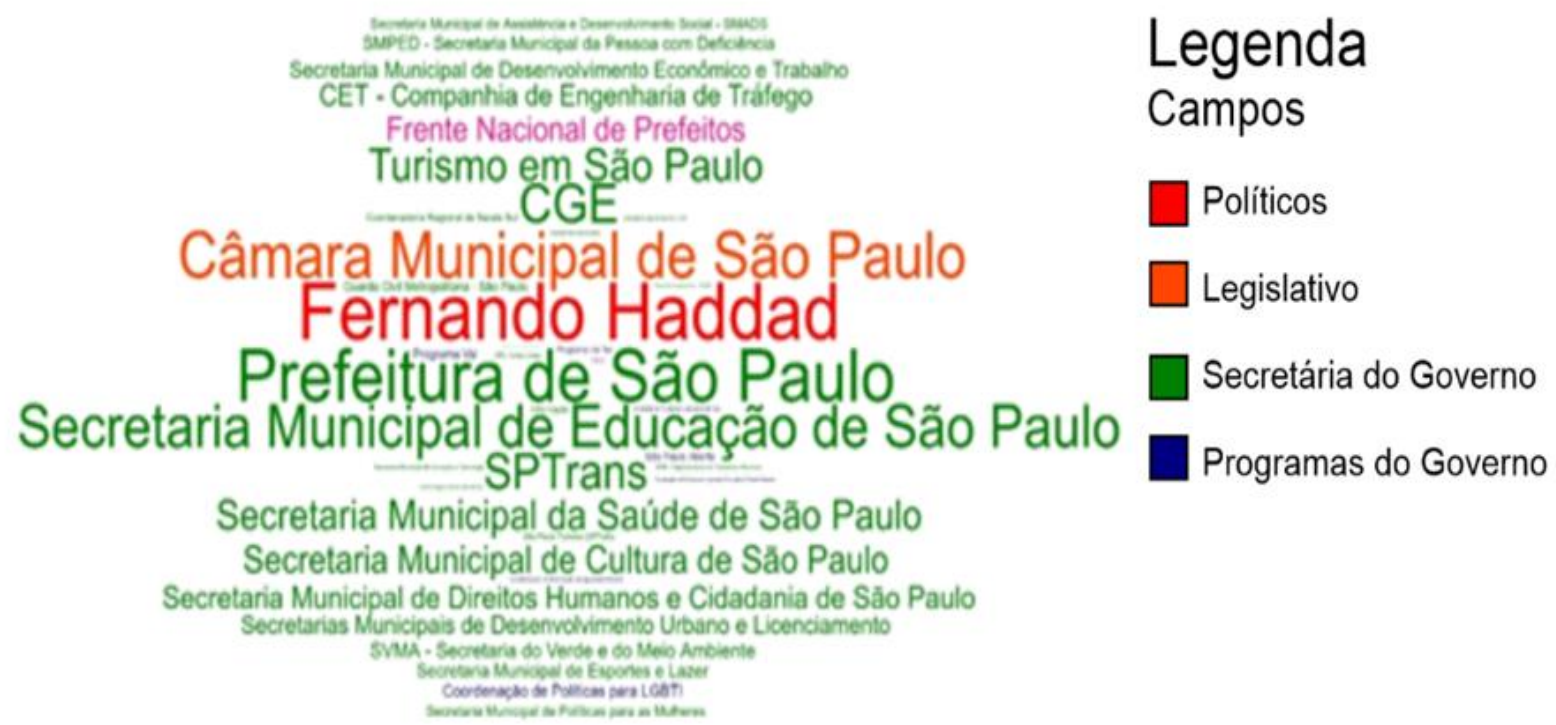

Fonte: Elaboração própria a partir dos dados primários do Facebook, outubro de 2018. 
A nuvem das agências culturais (figura 14), indica territórios, entre os quais o Centro Cultural São Paulo, o Teatro Municipal e o Auditório Ibirapuera, e programas de cultura, como o Dia da Música e a Praça das Artes. Os likes são gerados pelos cidadãos que consomem os produtos culturais do governo municipal. Rede do governo e ao mesmo tempo dos cidadãos, formada por quem reconhece a importância da cultura, essa rede transcendente e centralmente organizada, reproduz as relações de poder político da modernidade. As tecnologias transformam os processos de comunicação no espaço e com ela o exercício da política.

Figura 14. Nuvem de palavras. Campo das agências culturais da rede Haddad

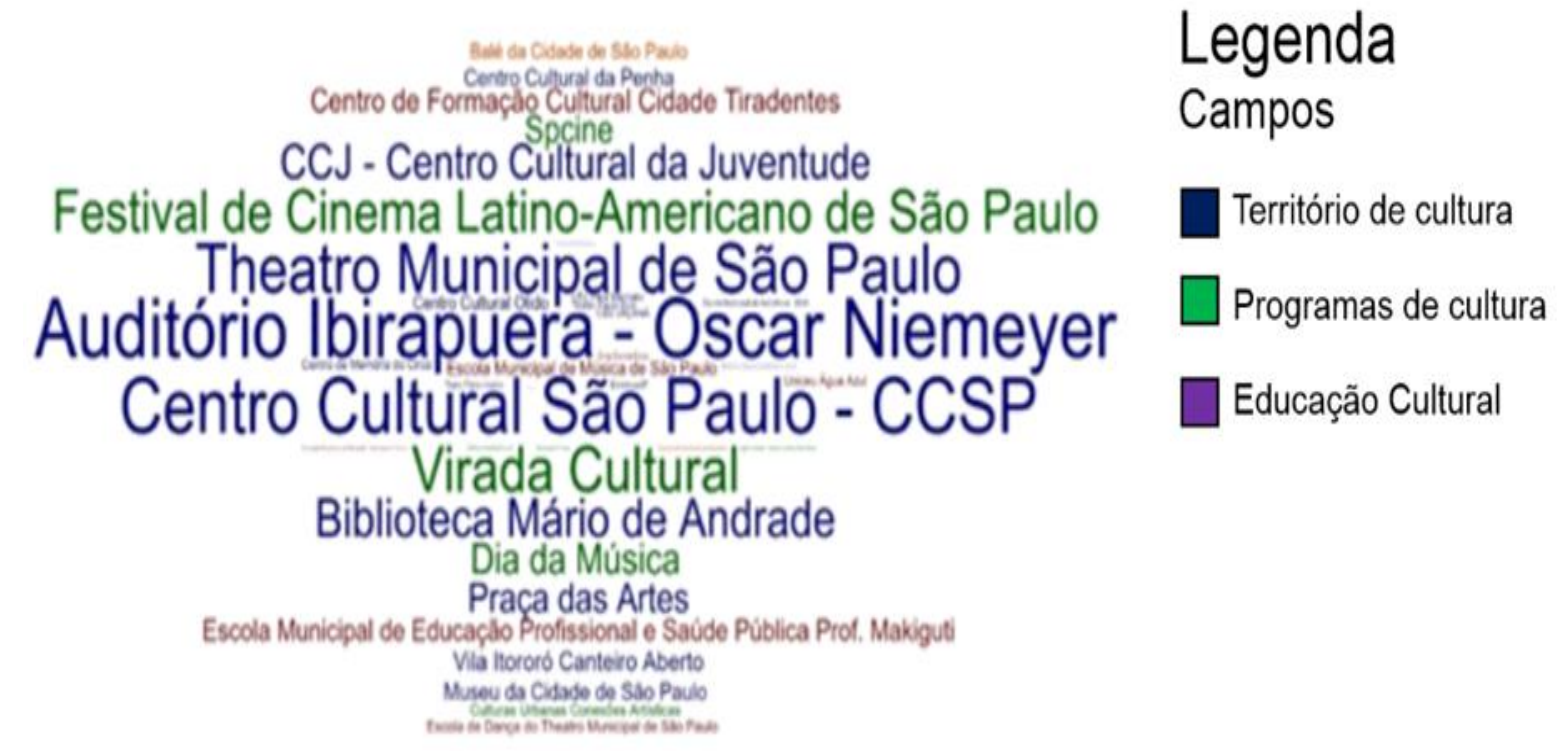

Fonte: Elaboração própria a partir dos dados primários do Facebook, outubro de 2018.

Em outras palavras, a campanha do Haddad ignorou a possibilidade de usar as plataformas digitais e suas redes para fazer política. A relação entre a campanha do Jair Bolsonaro com a campanha de Fernando Haddad mostrou-se extremamente desigual, são em torno de 900 milhões likes, para 550 mil, na base de vinte para um, o que é muito grave. Como seria possível para Haddad e seus partidários ganharem a eleição?

\section{Tecnopolítica e dominação norte-americana no Brasil}

Quando, em seus discursos, afirma estar defendendo a democracia, Jair Bolsonaro está se referindo ao amplo poder que essa rede lhe confere. Na realidade, o que o presidente está defendendo são os interesses políticos e econômicos dos atores membros da rede tecnopolítica que está tomando conta do Brasil. Esses agentes formam um corpo social coeso, que se move de acordo com objetivos políticos e econômicos muito claros. Basta observar os fatos concretos da vida real, como a entrega do pré-sal, a privatização das empresas públicas, a presença de empresas internacionais na formação de clusters, a aceleração do desmatamento da Amazônia para dar lugar ao agronegócio, a destruição de políticas públicas voltadas para o bem-comum e a liberação de porte de armas, para citar as mais importantes. 
A tecnopolítica atravessa fronteiras, fixando no país uma cadeia de atores americanos que deixa suas marcas no território nacional. Existe uma associação efetiva entre a rede internacional dominada pelos EUA e a rede nacional, capitaneada por seus seguidores no Brasil. A presença de atores internacionais na política brasileira não é uma novidade; a novidade está no fato de eles intervirem pela mediação de redes tecnopolíticas ${ }^{29}$, compartilhando um mesmo discurso e produzindo uma ação política em prol de uma ideologia de extrema-direita. Eles constituem um ator político de importância estrutural no contexto da crise da democracia no mundo.

Não menos importante é a violência permanente que permeia a subjetividade bolsonarista. Essa violência expressa-se nos ataques constantes às instituições democráticas, na indiferença pelo outro, na mentira cotidiana, no forte autoritarismo, na crueldade com os diferentes, na onipotência destrutiva em relação a seus oponentes. Outro elemento crucial é a manipulação de dados que flui pela rede. Referimo-nos à produção de fake news que gera desinformação e que tem por objetivo criar uma realidade fictícia ${ }^{30}$, permitindo-lhe transformar as pessoas em objetos de sua perversão.

O exame dessa rede, que coloca lado a lado agentes dos EUA e do Brasil, permite-nos afirmar que estamos diante, sem dúvida alguma, de uma cooperação entre os governos dos dois países, na qual os primeiros exercem uma dominação inconteste. Foi esse mesmo modelo de campanha eleitoral em rede tecnopolítica que elegeu Donald Trump presidente dos EUA, que garantiu a vitória ao Brexit no Reino Unido, que produziu a morte de 800 mil pessoas em Ruanda e que abriu caminho para um regime de extrema-direita na Ucrânia. Ele teria sido usado em nada menos do que 48 países $^{31}$.

Estamos diante de uma rede internacional que promove um mesmo sistema de desinformação no mundo. Associado a uma ideologia de direita, ele replica, em diferentes países, o modelo de campanhas que foi aplicado com tanto êxito nos Estados Unidos e no Brasil ${ }^{32}$. Vale destacar aqui a contradição entre o discurso contra a globalização e a participação dos EUA nos blocos de poder. Na verdade, o objetivo dessa rede global é promover um deslocamento do sistema de dominação, agora centrado nos EUA.

Somos alvo de uma guerra simbólica, ou hibrida, como prefere Korybko, que prescinde de armas letais, mas que sufoca as instituições democráticas, as empresas nacionais, as instituições de ciência e da tecnologia, as manifestações culturais, a vida social, a educação e a saúde da sociedade. Essa rede tecnopolítica, ao unificar atores nacionais e internacionais pela mediação de tecnologias digitais, assume o controle do país e coloca em xeque a existência do Brasil como nação democrática e soberana.

\section{Agradecimentos}

Agradecemos à Sergio Lamarão a precisa e clara revisão do artigo, que nos permite representar com rigor a nossa análise.

\footnotetext{
${ }^{29}$ Para usar o conceito de Empoli (2020).

${ }^{30}$ Kakutani, 2018.

${ }^{31}$ Korybko, 2018

${ }^{32}$ Ver o documentário Privacidade hackeada <https://www.netflix.com/br/title/80117542>.
} 


\section{Referências bibliográficas}

ALVARENGA, Camila; ALTMAN, Breno; AMADEU, Sérgio. 20 minutos: Sérgio Amadeu defende forte regulação das redes sociais. Opera Mundi UOL, Madri, Espanha. p. 1-2, 26 abr. 2021. <https://operamundi.uol.com.br/20-minutos/69472/20-minutos-sergio-amadeu-defendeforte-regulacao-das-redes-sociais $>$ [Consulta: 19 julho de 2021].

ARENDT, Hanna. A dignidade da política. Rio de Janeiro: Relúme-Dumara, 1994.

MORAIS, Roberto. O Partido Militar no (des)governo Bolsonaro: leituras sobre coesões e desconcertos feitas pelo Grupo de Estudos de Defesa e Segurança Internacional (GEDES) da Unesp. Blog do Roberto Morais. <http://www.robertomoraes.com.br/2020/06/passada-maisuma-semana-o.html > [Consulta 16 abril de 2020].

BOLSONARO, Jair Messias. Página Facebook Jair Messias Bolsonaro, 2018. <https://www.facebook.com/jairmessias.bolsonaro> [Consulta: 20 de abril de 2021].

BOLTANSKY, Luc. Usos fracos e usos intensos do habitus. In: ENCREVÉ, Pierre. Trabalhar com Bourdieu. Rio de Janeiro, Bertrand Brasil, 2005.

BOMFIM, Emanuel. 'Notícia No Seu Tempo': lobistas de armas tiveram pelo menos 73 audiências no governo, interior supera capital em casos de covid e um concerto para plantas em Barcelona. Jornal Estadão, 23 jun. 2020. <https://brasil.estadao.com.br/blogs/estadaopodcasts/noticia-no-seu-tempo-lobistas-de-armas-tiveram-pelo-menos-73-audiencias-nogoverno-interior-supera-capital-em-casos-de-covid-e-um-concerto-para-plantas-embarcelona/> [Consulta: 16 fevereiro de 2021].

BOURDIEU, Pierre. A distinção. Crítica social do julgamento. São Paulo: EDUSP; Porto Alegre: Zouk, 2007b.

BOURDIEU, Pierre; CHAMBORDEN, Jean Claude; PASSERON, Jean-Claude. Ofício de sociólogo. Metodologia na pesquisa. Petrópolis: Vozes, 2007a.

CASTELLS, Manuel. A ruptura: crise da democracia liberal. Rio de Janeiro: Zahar, 2017.

CHOMSKY, Noam. Mídia: propaganda política e manipulação. São Paulo: Editora WMF, 2013.

EGLER, Tamara Cohen. Pequeno ensaio: do campo para a redesociotecnica In: MARTELETO, Regina. Pierre Bourdieu e a produção social da cultura, do conhecimento e da informação. Rio de Janeiro: Garamond, 2017. 305-323p.

EMPOLI, Giuliano. Os engenheiros do caos. São Paulo: Vestígio, 2020.

FERGUNSON, Nial. A praça e a torre. São Paulo: Planeta do Brasil, 2018. 
Jornal $O$ Globo. Bolsonaro não é louco. <https://blogs.oglobo.globo.com/ruth-deaquino/post/bolsonaro-nao-e-louco.html> [Consulta: 20 de maio de 2020].

Jornal Valor Econômico. Christian Klein. Militarização nunca saiu do horizonte político. $<$ https://valor.globo.com/politica/noticia/2020/06/16/militarizacao-nunca-saiu-do-horizontepolitico.ghtml>. [Consulta: 6/06/2020].

KAKUTANI, Michico. A morte da verdade. Rio de Janeiro: Intrínseca, 2018.

KLEIN, Cristian. Militarização nunca saiu do horizonte político. Valor Econômico, Rio de Janeiro, Brasil, $16 \quad$ jun. 2020. <https://valor.globo.com/politica/noticia/2020/06/16/militarizacao-nunca-saiu-do-horizontepolitico.ghtml> [Consulta: 12 abril de 2021].

KORYBKO, Andrew. Guerras híbridas. São Paulo: Expressão Popular, 2018.

LAGRAVE, Rose Marie. Trabalhar com Bourdieu. Rio de Janeiro: Bertrand Brasil, 2005.

Portal G1. Laís Lis. Governo Bolsonaro mais que dobra número de militares em cargos civis, aponta TCU. <https://g1.globo.com/politica/noticia/2020/07/17/governo-bolsonaro-tem-6157militares-em-cargos-civis-diz-tcu.ghtml> [Consulta: 24 março de 2021].

MARTINS, Paulo Henrique. Redes sociais. Como novo marco interpretativo das mobilizações. In Tomael, Maria Ines; Marteleto, Regina Maria (Org). Informação e Redes Sociais. Londrina: Eduel, 2015.

MEMBE, Achille. Necropolitica. São Paulo: N-1 Edições, 2018.

TOMAÉL, Maria Inês; MARTELETO, Regina. Mobilizações coletivas contemporâneas: outras perspectivas. Informação e redes sociais, interface de teorias, métodos e objetos. Londrina: EDUEL, 2015, 183-217p.

MORIN, Edgard. Por uma reforma do pensamento. In PENA-VEGA, Alfredo; NASCIMENTO, Elimar P. O pensar complexo: Edgard Morin e a crise da modernidade. Rio de Janeiro: Garamond, 1999, 7-21p.

PENNA, Manuel; FREY, Klaus; CZARJKOWSKI, Sergio. Avaliação estrutural das redes sociais. In EGLER, Tamara (org.). Ciberpólis: redes no governo da cidade. Rio de Janeiro: Sete Letras, 2007, 47-69 p.

PRIVACIDADE Hackada. Direção: Karim Amer; Jehane Noujaim. Roteiro: Karim Amer; Pedro Kos. EUA: Netflix, 2019. <https://www.netflix.com/br/title/80117542> [Consulta: 16 novembro de 2020]

Portal Brasil 247. Quem são os empresários que apoiam Bolsonaro e que poderão sofrer boicotes. <https://www.brasil247.com/brasil/empresarios-bolsonaristas-colhem-umaeconomia-em-frangalhos-e-podem-sofrer-boicotes $>$. [Consulta: 19 de maio de 2021]. 
RIBEIRO, Ana Clara Torres. Sociologia do presente: ação, técnica e espaço. Rio de Janeiro: Letra Capital, 2011.

SAFATLE, Vladimir. O circuito dos afetos. Corpos políticos, desamparo e o fim do indivíduo. Belo Horizonte: Autêntica, 2018.

SANTOS, Milton. Técnica, espaço, tempo: globalização e meio técnico-científico informacional. São Paulo: Hucitec, 1994.

SCHERER-WARREN, Ilse. Redes sociais: trajetórias e fronteiras. In DIAS, Leila; SILVEIRA, Rogério (org.). Redes, sociedades e territórios. Santa Cruz do Sul: EDUNIC, 2005, 11-24 p.

SOUZA, Joao Carlos; MORAES, Ricardo. A mobilização cívica e política na era das redes sociais: uma análise da ação de movimentos sociais no Facebook. Opinião pública, Campinas, $\begin{array}{llllll}\text { vol } 27, & \mathrm{n} & 1, & \text { jan } & - \text { abril, } & 2021 .\end{array}$ <https://www.scielo.br/j/op/a/DV3qXGcwPDBSFr53RdMHQFL/?lang=pt>.

TIBURI, Marcia. Delírios do poder. Rio de Janeiro: Record, 2019.

SOUZA, João Carlos; MORAES, Ricardo, 2012. A mobilização cívica e política na era das redes sociais uma análise da ação de movimentos sociais no Facebook.

TOMAÉL, Maria Inês; MARTELETO, Regina Maria. Redes sociais de dois modos:

Aspectos conceituai. Transformação, Campinas, 25(3):245-253, set./dez., 2013. <https://www.scielo.br/j/tinf/a/L7QwLS5RZ5JwffJ5Bxrzc4v/?format=pdf\&lang=pt>.

Huff Post Brasil. <https://www.huffpostbrasil.com/entry/1-ano-decretoarmas_br_5e1f57b6c5b673621f6f73ae>. [Consulta em 20 de janeiro de 2020].

Web Site Câmara dos Deputados do Brasil <https://www.camara.leg.br/noticias/622252-joicehasselmann-denuncia-milicia-e-gabinete-de-odio-na-disseminacao-de-fake-news/> [Consulta 20 de dezembro 2020].

Ficha bibliográfica:

EGLER, Tamara Tania Cohen; COSTA, Thiago; GONÇALVES, Pedro Paulo. A (in)visibilidade da rede tecnopolítica bolsonarista. Ar@cne. Revista Electrónica de Recursos de Internet sobre Geografí y Ciencias Sociales. Barcelona: Universidad de Barcelona, I de octubre de 202I, vol. XXV, $\mathrm{n}^{\circ}$ 259. DOI: https://doi.org/10.1344/ara2021.259.36699 